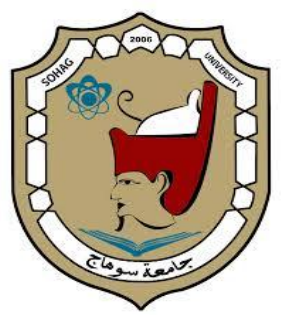

$$
\begin{aligned}
& \text { جامعة سو هاج } \\
& \text { كلية التربية } \\
& \text { قسم تكنولوجيا التعليم }
\end{aligned}
$$

\title{
توظيف بعض تطبيقات البمال في التدريب عن بعد لتنمية مهارات استفدام هواقع البث المباشر في التدريس لدى أعضاء هيئة التدريس
}

$$
\text { إعداد }
$$

د/هممد همثود عبدالوهاب

أستاذ تكنهولوجيا التمايم المساعد

كلية التزبية - جامهمة سوهاج 
يشهد العالم اليوم ثورة تكنولوجية وتقنية فرضت نفسها على طبيعية الحياة؛ أسهمت في تغيير نمط الحياة

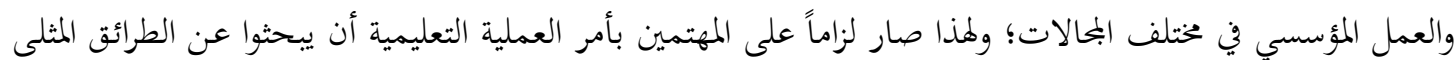
للارتقاء بالعملية التعليمية والتدريبية وبحويدها ليتماشى مع نمط التقدم الحادث.

ولهـا يتسـارع العـا لم اليـوم لاكتشـاف التقنيـات الحميثـة وتوظيفهـا التوظيـف الأمثـل في العمليـة التعليميـة

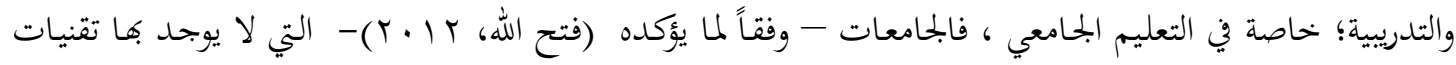
تكنولوجية حديثة تصبح جسداً بلا روح، وإذا وجدت هذه التقنيات ولم تستخدمها تصبح جسداً بلا أقدام.. ويدفع التقدم الكبير في تكنولوجيا المعلومات والاتصالات الذي نشهده اليوم يدفع باتحاه التغيير الشامل في جميع مناحي الحياة، وبخاصة التعليمية منها؛ هذا التطور الحالي أحدث ثورة معرفية يصعب التنبؤ بمعدلات انتشارها،

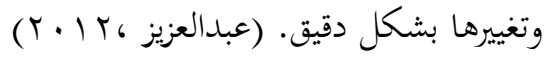

وقد مر استخدام المستحدثات التقنية في تطوير المؤسسات التعليمية بمراحل عديدة ؛ بدءًا بمرحلة توظيف الحاسب الآلي في التدريب والتعليم، ثم ظهور مفهوم التعلم الإلكتروين الذي أعتمد بتوظيف أدوات الانترنت، ووصولاً لمفهوم جديد هو التعلم عبر استخدام التعلم بـالجوال الذي يسعى للاستفادة مـ تقنية الاتصالات اللاسلكية. ( مهدى، (T)

ويُعد التعلم الجوال واحدا من المستحدثات التقنية المهمة في العمليات التعليمية والتدريبية المختلفة ؛ وذلك نظرا لاتساع انتشاره والسهولة في استخدامه وإمكانية ربطه بشبكات الانترنت، بالإضافة إلى أنه يسمح باستقبال تطبيقات متنوعة الوظائف بحيث يمكن توظيفها بشكل فعال في عمليات الاتصال والدعم المستمر، كما يمكن من خلال تلك الهواتف متابعة وتنفيذ الأنشطة الطلابية عبر رسائل الوسائط المتعددة التي تبث من خلاله وإرسال واستقبال الرسائل النصية والصوتية ورسائل الفيديو، الدخول إلى الانترنت، تشغيل الملفات المختلفة، تصفح مواقع الانترنت، تبادل

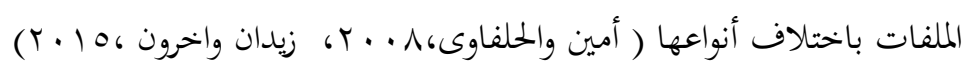

ومما يزيد من استخدام التعلم عبر الجوال ؛ كثرة أعداد تلك الأجهزة، وكثرة التطبيقات التي تعمل من خلالها والتي يمكن توظيفها في العملية التعليمية والتدريبية ، وكذلك انتشار أنماط التعلم عن بعد وحاجة المجتمع له، باعتبار هذا النوع من التعليم يسهم في حل مشكلة محدودية التعليم. (الدهشان ويونس ، 9 . . ب).

يضاف لما سبق أن استخدام تطبيقات الجوال يمكن أن تسهم بشكل ملموس في توفير ذلك النمط من التعلم القائم على الاستكشاف وحب الاستطلاع وبناء ثقة المتعلم بنفسه وقدراته، وزيادة دافعيته نحو التعلم نظراً لما يتمتع به من حداثة وتطور، كما يتيح التعلم باستخدام تطبيقات الجوال فرصاً هائلة للمعلمين تمكنهم من تقديم المقررات الدراسية بأسلوب شيق وجذاب (شحاته ، • ( • ؟). 
وانطلاقاً من هذا، فقد اهتمت كثير من الدول باستخدام تطبيقات الجوال في الميدان التربوي، ففي تفعيل استخدام تطبيقات التعلم بالجوال قامت إدارة التعلم النيوزلندية بتفعيل خدمة التعلم عن طريق خدمة SMS بحيث يقوم الطالب بإرسال رسالة نصية من خحلال جواله مستفسرا عن بعض المعلومات المرتبطة بموضوعات التعلم ، فتصله رسالة

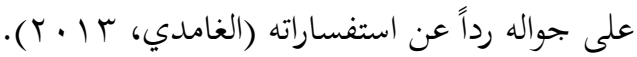

وقد أكدت نتيجة دراسة جوناس (Jonas,2012) أن العديد من المعلمين والطلاب يستخدمون تطبيقات الجوال في العملية التعليمية، باعتبارها أحد أهم التقنيات التي انتشرت بين المستخدمين بشكل سريع وهائل، حيث هناك اكثر من ه.r مليار هاتف جوال مستخدم في العالم ، وهذا يدل على انتشارها بمعدلات مذهلة ؛ سواء في البحال الاجتماعي والاقتصادي أو الثقافي. وجاء من أهم نتائج دراسة كل من ( Teng\&Helps 2010 Wasilewska \&Wong,2009 Chayko,2008 (Smith,2005 أن التعلم الجوال أصبح ظاهرة واضحة في المحال التعليمي بسبب كثرة المشتركين في استخدام تطبيقات تلك الأجهزة واستخدامها في الجوانب التعليمية والتدريبية على الرغم أن تلك الأجهزة صممت في المقام الأول للتواصل المباشر بين البشر تلبية لاحتياجاهم الاجتماعية.

هذا، وقد أوضحت نتائج دراسة موتيفالا (Motivalla,2007)أن المتعلمين قد وجدوا في استخدامهم لتطبيقات الماتف الجوال وسيلة بحانية للتفاعل الصفي واللاصفي ؛ وذلك لأن التعلم الجوال يتيح تفاعلا بناءً بين المعلمين والطلاب، كما يسمح بالإدارة الفاعلة للتفاعلات الخاصة بمناقشة الدروس التعليمية بين الأساتذة بعضهم البعض. وقد أكدت دراسة جنج (Jeng,2010) فاعلية استخدام التعلم الجوال في تنمية مهارات استخدام مواقع التعلم المرئي في بالتدريس. وقد أكد دراسة (Sampson \& Panagiotis,2013 ) فاعلية استخدام تطبيقات الجوال في التدريب عن بعد ، وذلك في عدة جوانب منها: المشاركة الفعالة لجميع المتدربين دون التقيد بالمكان أو الزمان ، وتقديم الدعم الفني الفوري سواء بالمصادر التعليمية - بغض النظر عن موقع المتدربين - أو أجهزةم المستخدمة ، وكذاً تمكين المتدربين من مواصلة أنشطتهم التدريية سواء داخل القاعات التدريبية او خارجها ، وذلك من خلال تفاعلهم وتواصلهم المستمر مع مدربيهم.

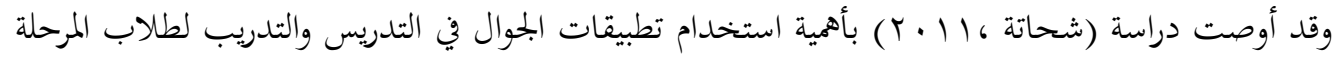
الجامعية عن بعد ، وذلك لما اثتبه الدراسة من أهمية التعلم باستخدام تطبيقات الجوال في تنمية الاتجاه نغو مستحدثات تكنولوجيا التعليم .

وتعتبر مواقع البث المباشر من الطرائق الحمديثة في التدريس لقدرتا على نقل المعلومات والمهارات بأقل وقت وأقل تكلفة ، وذلك مـن خلال إمكانية التواصل المتزامن وغير المتزامن بين المتعلمين والمعلمين في أي وقت وفي أي مكان باستخدام أدوات الويب الحديثة . 
ومن المؤكد أن حصر فوائد و إيهابيات مواقع البث المباشر في التدريس شي معقد لكثرة فوائدها في حال تم استخدامها بالشكل الصحيح ، حيـث بـدأت بعض المدارس والجامعات في استخدامها لبـث الدروس و المحاضرات للطلبـة ، لتكـون متاحـة للجميع ليتمكن أكبر قـدر مـن المتعلمـين بمتابعتها دون الحاجـة للحضور و قطع المسافات الطويلة.

ومن المعلوم أن اكتساب مهارات استخدام مواقع البث المرئي في التدريس يتطلب استخدام تقنية متقدمة وسهلة الاستخدام حتى يمكن اكتساب هذه المهارات واتقاغا؛ وهذا يتطلب اختيار أفضل الأساليب والطرق والتقنيات

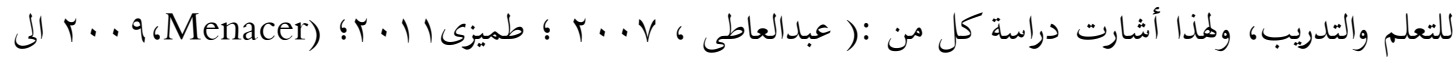
أهمية استخدام تطبيقات الجوال في التدريب عن بعد وتوظيفها التوظيف الأمثل في تعلم مهارات تقنية حديثة يمكن استخدامها أيضا في البمال التعليمي والتدريبي، ولذذا سعى البحث الحالي للتعرف على فاعلية توظيف تطبيقات الجوال في التدريب عن بعد لتنمية مهارات استخدام مواقع البث المباشر في التدريس لدى أعضاء هيئة التدريس.

\section{هشكلة البمث:}

نظراً للدور المهم والمتوقع من فاعلية تطبيق تكنولوجيا التعلم عبر الجوال في العملية التعليمية والتدريبية فقد تعددت المؤتمرات العالمية والإقليمية التي أهتمت بهذا الجانب ، وأوصت معظمها بأهمية الأخذ بالمستحدثات التكنولوجية وبخاصة التعلم عبر الجوال في مجال التعليم والتدريب عن بعد ؛ والذي يوفر نوعية تعلم وتدريب جيدة ،

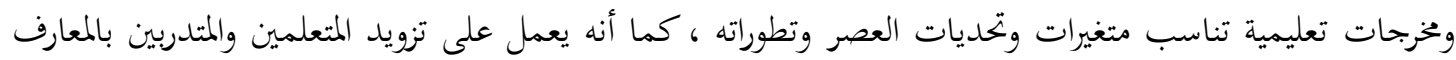

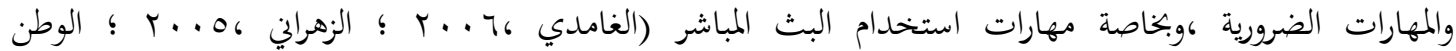

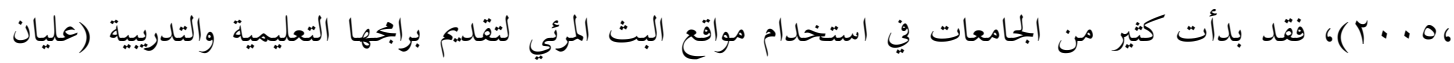

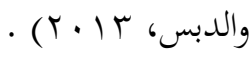

وقد أكدت عديد من نتائج الدراسات والبحوث السابقة أهمية استخدام تطبيقات التعلم الجوال وتوظيفه التوظيف الأمثل في عملية التعليم والتدريب عن بعد وبخاصة في تعليم وتدريب المعلمين علي مهارات استخدام البث المباشر في التدريس ، وذلك سعيا لتحقيق الترشيد في خفض تكاليف تطوير الأداء التدريسي، وتحقيقا لمبداً شمولية التدريب والتعليم ليشمل ويعم الجميع داخل وخارج المؤسسات التعليمية؛ ومن هذه الدراسات دراسة كل من (بدر ،

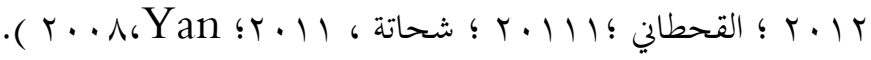

وقد لاحظ الباحث من خلال عمله كمدرب لاستخدام التقنية في التدريس بالجامعة الإسلامية بالمملكة العبية السعودية عدم استخدام أعضاء هيئة التدريس لمواقع البث المباشر في التدريس وذلك لافتقارهم لمهارات استخدام هذه المواقع على الرغم من أهميتها في تطبيق آليات التدريس المتزامن وغير المتزامن. وقد قام الباحث بدراسة استطلاعية على عينة من أعضاء هيئة التدريس بالجامعة الإسلامية بالمدينة المنورة قوامها (10) عضواً ، وذلك للتعرف على مدى اتقاغم لمهارات استخدام مواقع البث المباشر في التدريس بشكل 
خاص واستخدام تطبيقات الجوال بشكل عام. وقد أوضحت نتيجة الدراسة عدم معرفة أفراد العينة بتلك المواقع وقلة استخدامهم للتعلم باستخدام الجوال في العملية التعليمية. ويوضح الجحدول (1) النتائج الخاصة بمستوى اتقان أفراد العينة لمهارات استخدام مواقع البث المباشر: - ماتم

\begin{tabular}{|c|c|}
\hline مستوى الاتقان & المهارة \\
\hline$\%$ \% & مهارات استخدام موقع Nearpod للبث المباشر \\
\hline$\% 1$ & مهارات استخدام موقع Bambuesr للبث المباشر \\
\hline \%rr & استخدام تطبيقات الجوال في التدريس \\
\hline
\end{tabular}

تأسيساً على ما سبق، فقد جاء هذا البحث للتعرف على فاعلية توظيف تطبيقات الجوال في التدريب عن بعد لتنمية بعض مهارات استخدام مواقع البث المباشر في التدريس لدى أعضاء هيئة التدريس .

أسئلة البمث: حاول البحث الحالي الاجابة عن السؤال الرئيسي الآتي: ما فاعلية توظيف تطبيقات الجوال في التدريب عن بعد لتنمية مهارات استخدام مواقع البث المباشر في التدريس لدى

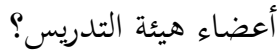
، ويتفرع من هذا السؤال الرئيس الأسئلة الفرعية الآتية: - - ما مهارات مواقع البث المباشر الواجب توافرها لدى أعضاء هيئة التدريس؟ ץ- ما التصميم المقترح لتوظيف تطبيقـات الجـوال في التدريب عن بعد لتنمية مهارات استخدام مواقع البـث المباشر في التدريس التعلم لدى أعضاء هيئة التدريس؟ ب- ما فاعلية توظيف تطبيقات الجموال في التدريب عن بعد لتنمية الجانب المعرفي لبعض مهارات مواقع البث المباشر في التدريس لدى أعضاء هيئة التدريس؟ ع - ما فاعلية توظيف تطبيقات الجوال في التدريب عن بعد لتنمية الجانب الأدائي لاستخدام مواقع البث المباشر في التدريس لدى أعضاء هيئة التدريس؟ 
وضع تصميم مقترح لتوظيف تطبيقات الجوال في تنمية مهارات استخدام مواقع البث المباشر في التدريس لدى

اعضاء هيئة التدريس بالجامعة الاسلامية؟ كئج

ه الكشف عن فاعلية التصميم المقترح لتوظيف تطبيقات الجوال في زيادة الجانب التحصيلي لمهارات استخدام

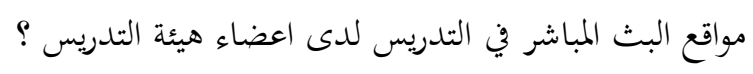

الكشف عن فاعلية التصميم المقترح لتوظيف تطبيقات الجوال في تنمية مهارات استخدام مواقع البث المباشر في

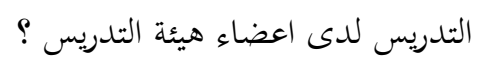

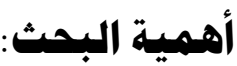

أكتسب البحث الحالي أهميته مما يلي: - n

توظيف أحد تقنيات ومستجدات العصر في التعليم والتدريب عن بعد، ومحاولة الاستفادة من تقنية الجوال المتوفرة لدى معظم الطلاب في المرحلة الجامعية.

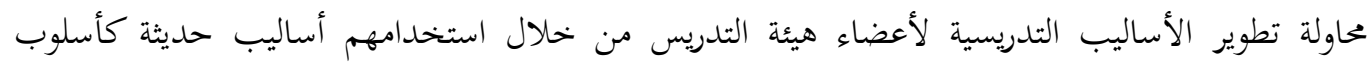
التعليم والتدريب باستخدام الجوال، والذي يعتمد بصورة أساسية على التطور التقني.

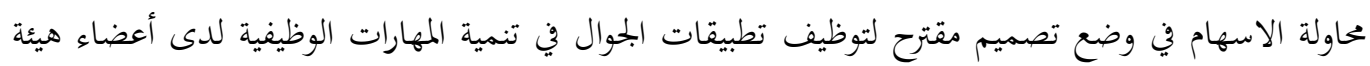
التدريس وبخاصة تلك المهارات المرتبطة باستخدام التقنيات الحديثة.

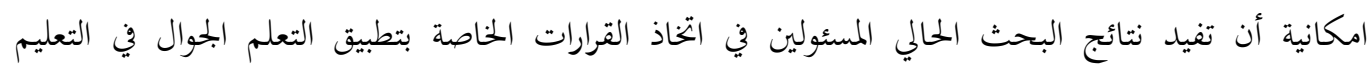
والتدريب والتعليم عن بعد.

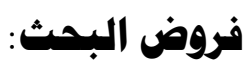

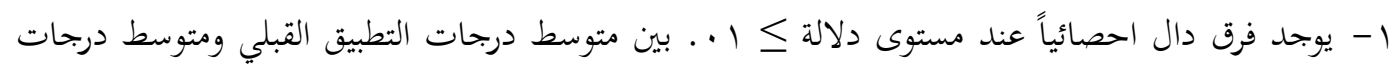

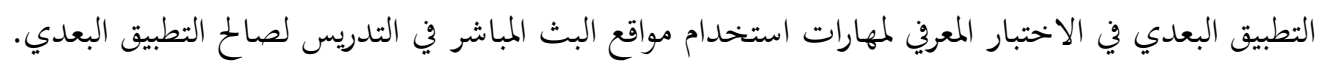

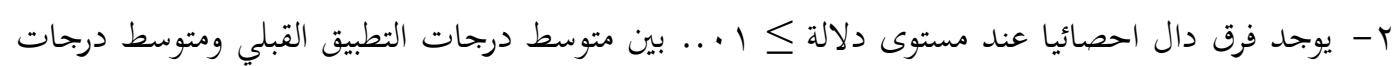

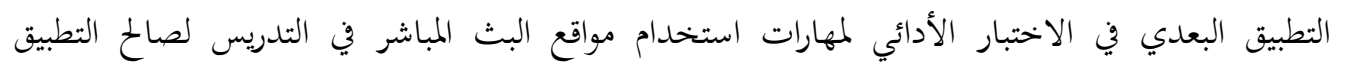

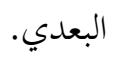

هوتثثلت تطبيقات الجوال المقترحة لتنفيذ البرنامج عن بعد في التطبيقات التالية: ( Mobile Learning وتطبيق

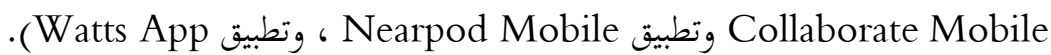
• اقتصرت عينة البحث على بحموعة من أعضاء هيئة التدريس بالجامعة الإسلامية حلى عمل الباحث.

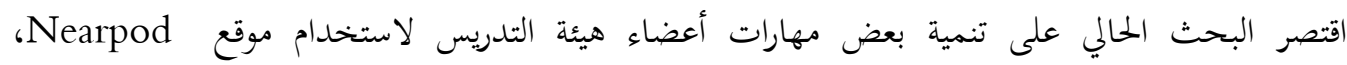
bambuser خدمتهم البحانية في البث المباشر. 

استخدم الباحثث المنهج الوصفي التحليلي لتحديد مهارات استخدام مواقع البـث المباشر، كمـا

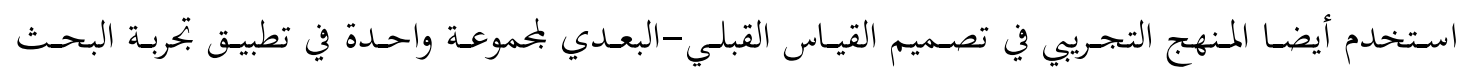

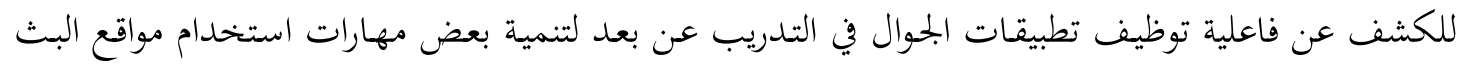
المباشر فن التدريس لدى أعضاء هيئة التدريس.

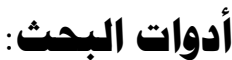

لتحقيق أهداف البحث ، والتحقق من صحة فروضه ، قام الباحث بإعداد الأدوات التالية:

$$
\text { 1- ا- اختبار تحصيلي معرفي لبعض مهارات استخدام مواقع البث المباشر المبان }
$$

\section{عينة البحث}

تكونت عينة البحث من (·r) عضو هيئة تدريس بالجامعة الإسلامية تم اختيارهم بناء على رغبتهم في تسجيل

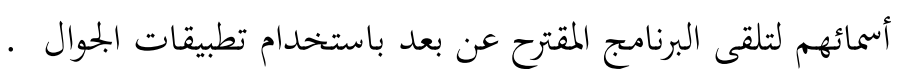

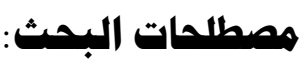

$$
\text { تطبيقات الجوال }
$$

تعرفها العمرى (10 ب ب) باها "نوع من البربحيات المصممة للعمل من خلال الأجهزة النقالة، عن طريق ربطها بخدمة الانترنت لمساعدة المعلمين والطلاب في عملية التعلم.

ويعرف الباحث تطبيقات الجوال اجرائيا بانها " برامج مصممة للعمل من خلال المواتف النقالة بحيث يتم

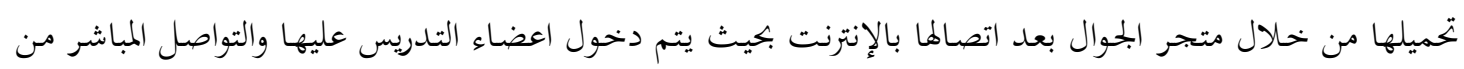
خلالما بطلافمم في أي وقت وباي مكان.

$$
\text { التدريب عن بعد }
$$

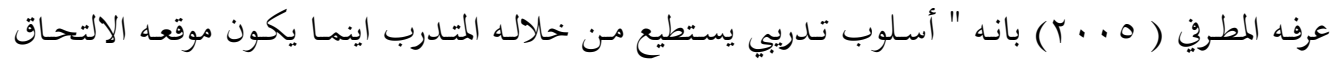

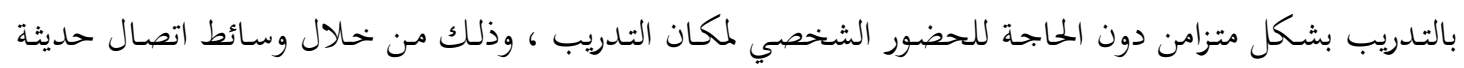
ووسائط متعددة اخرى. 
يقصد به إجرائيا في هذا البحث بأنه " برنامج يبنى من بحموعة من المهارات المخطط والمنظم لها ، وتعرض من خحلال تطبيقات الجوال بحيث يتم تدريب اعضاء هيئة التدريس عليها لرفع كفاءقم في استخدام مواقع البث المباشر في التدريس.

\section{مواقع البث المباشر}

يعرفها الباحث إجرائيا بهذا البحث بأها " مواقع عبر شبكة الانترنت تم تصميمها بلغة HTML من اجل البث المباشر وغير المباشر للتواصل المتزامن وغير المتزامن بين المعلم وطلابه في أي وقت وفي أي مكان ، بحيث يتم عرض المعلومات او المهارات العملية على الطلاب .

\section{مهارات مواقع البث المباشر}

يعرفها الباحـث إجرائيـا بهـا البحثث بأهـا " بحموعـة مـن المهارات المتعلقـة باستخدام مـوقعي ( nearpod ، bambuser ) للتواصل المتزامن بـالمتعلمين لنقل المعرفـة والمهارة في أي وقت وفن أي مكان باقل تكلفـة باستخدام

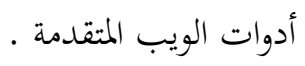

\section{الإطار النظري للدراسة}

لما كانت الدراسة الحالية تستهدف التعرف على فاعلية توظيف تطبيقات الجوال في التدريب عن بعد لتنمية

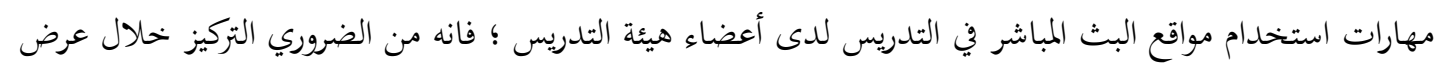
أدبيات هذه الدراسة على العناصر التالية: مفهوم التعلم بالجوال، معايير تصميم بيئات التعلم الإلكتروني القائمة على له استخدام الجوال ، أسباب توظيف تطبيقات الجوال في بيئات التعلم الإلكتروي في التدريب والتعليم ، التجارب الرائدة

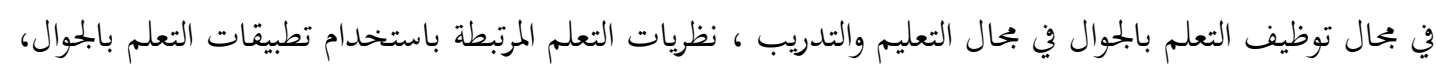
مزايا استخدام مواقع البث المباشر في التدريس، مراحل بناء برامج التدريب عن بعد.

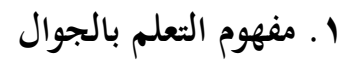

تعددت التعريفات التي قدمها الباحثون لمفهوم التعلم بالجوال ، فقد بنى دومى (^ . . ب) على انه القدرة على

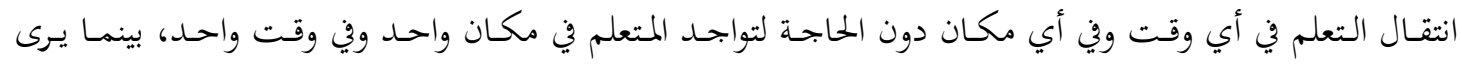

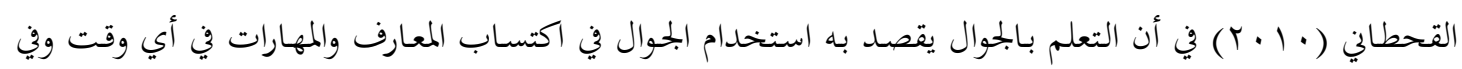

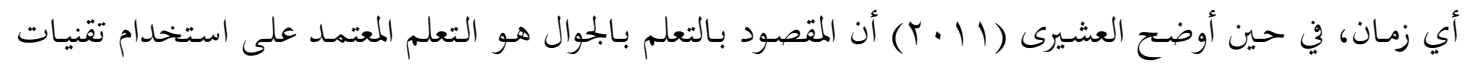

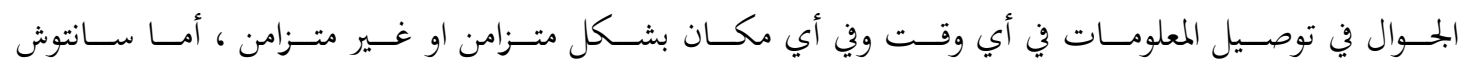
فقد بين بأن المقصود بالتعلم بالجوال ذلك النوع من التعليم الذى يتيح حرية التعلم دون التقيد بحاجز الزمان والمكان في ايصال المحتوى العلمي للمتعلمين. يتضح مما سبق ، أن جملة التعريفات التي قدمها الباحثون أعلاه حول مفهوم التعلم بالجوال ركزت على الآتي: 


$$
\text { - - - - عدم التقيد بحاجز الزمان والمكان في عملية التعلم. }
$$

ويمكن تعريف التعلم بالجوال إجرائياً "بأنه ذلك النوع من التعلم الذى يعتمد على تطبيقات الجموال في توصيل المفاهيم واكتساب المهارات للمتعلمين دون التقيد بحاجز الزمان او المكان مـن خهلال التواصل المتزامن وغير

\section{r r معايير توظيف تطبيقات الجوال في بيئات التعلم الإلكتروني.}

هناك بحموعة من المعايير العامة لتوظيف تطبيقات الجوال في بيئات التعلم الإلكتروني حددها كل من عقل

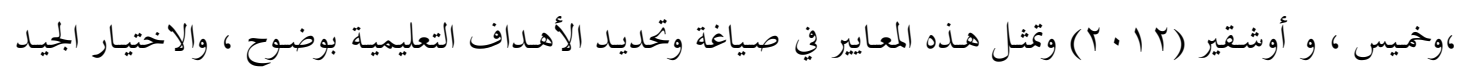
لعناصر التعلم ، مع توفير تغذية راجعة وتقويم مناسب لعناصر التعلم ، مع احتواء عناصر التعلم على وسيط تعليميي مناسب ، والبساطة في الاستخدام ، مع توفير إرشادات وتعليمات الاستخدام الصحيح . أما عن معايير توظيف تطبيقات الجوال في بيئات التعلم الإلكتروني ، فقد حددها الدهشان (rا • r ) في الآتى:

$$
\begin{aligned}
& \text { 1- تحديد نوع التعلم المناسب للموقف التعليمي. } \\
& \text { r- تطوير تطبيقات مناسبة للمحتوى المقدم من خلالها. } \\
& \text { r- بتهيز المواد التعليمية بشكل متناسب مع تطبيقات التعلم بالجوال. } \\
& \text { ع - توفير الدعم اللازم لتفعيل التعلم بالجوال. }
\end{aligned}
$$

في ضوء المعايير السابقة بند أن توظيف تطبيقات الجوال في بيئات التعلم الإلكتروني تحتاج الى تصميم المحتوى بشكل يناسب مع تطبيقات التعلم بالجوال ، وكذا المواد التعليمية وعناصر التعلم يجب تجهيزها بشكل مـدعم لأنظمة الجوال ، مع توفير الارشادات والتغذية السليمة لعناصر التعلم .

r. أسباب توظيف تطبيقات الجوال في بيئات التعلم الإلكتروني في التدريب والتعليم:

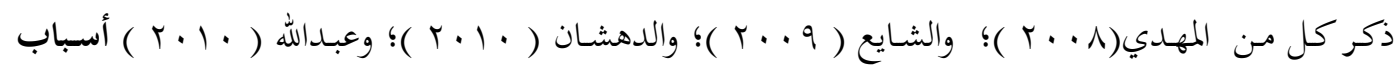
توظيف تطبيقات الجوال في بيئات التعلم الإلكتروني في التدريب والتعليم على النحو الآتي:

$$
\text { كثرة الزيادة الهائلة في استخدام التواصل باستخدام الجحوال بين الناس في العالم. }
$$

يساعد التعلم بالجوال زيادة فرص التعلم بالاكتشاف عن طريق القراءة والتدريبات وفقاً للنظرية البنائية. 


$$
\text { مساعدة المتعلمين ذوى الاحتخدام التعلم بالجوال فرص التغلب على الرهبة من التعامل مع التقنيات الحديثة . }
$$

تنوع وزيادة الأنشطة التفاعلية للدروس مما يخلق بيئة أكثر جاذبية وتشويقيا للعملية التعليمية والتدريبية .

$$
\text { التعدد التطبيقات المعتمدة على الجوال في المحال التدريبي والتعليمي. }
$$

وجملة هذه الأسباب متوفرة في بيئة التعلم الخاصة باستخدام الجوال ، وهذا ما دفع الباحث إلى اجراء الدراسة الحالية ، حيث أصبح التعليم عن بعد ،وكذا التدريب عن بعد أحسدى الضرورات المهمة في عمليتي التعليم

والتعلم ، والتدريب المرتبط بتحقيق التنمية المهنية للمعلمين اثناء الحندمة.

ع. التجارب الرائدة في مجال توظيف التعلم بالجوال في مجال التعليم والدريب:

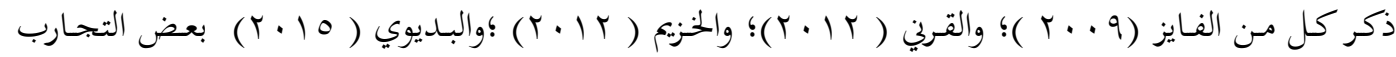

الرائدة في بحال تطبيق التعلم بالجوال في العملية التعليمة والتدريبة وتمثلت تلك التجارب في الآتي:

\section{ا - تجربة جامعة ولاية وسيكل ستايت الامريكية}

حقق تطبيق التعلم باستخدام الجوال تقدماً ملحوظا في مستوى أداء ابخاز المتعلمين للمهام التعليمية ، وحل

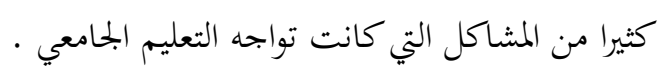

r- ( ب التجربة الفلبينية

تم استخدام التعلم في الجوال في ايصال العملية التعليمية للمتعلمين في الأماكن البعيدة بأنحاء البلاد ، وقد اثتتت هـذه التجربة فاعلية التعلم باستخدام تطبيقات الجهوال في تطوير العملية التعليمية سواء في التعليم الجحامعي او التعليم قبل الجامعي ، وذلك نظرا لمرعاه الفروق بين المتعلمين وكل متعلم يتعلم وفقا لقدراته

$$
\begin{aligned}
& \text { وامكانياته وكذا حسب الوقت المتاح له. } \\
& \text { ب- التجربة الامريكية }
\end{aligned}
$$

تم تطبيق هـذه التجربـة لاستخدام التعلم الجحوال في التعليم وذلك بالمـدراس والمعاهـد الحكومية والخاصـة ، وأصبحت تمارس من قبل عدد كبير من المعلمين والطلاب ، وكانت تحربة اثبتت فاعليتها في العملية التعليمية من حيث سرعة انتشارها ووصول التعلم الى الطلاب في وقت وفي أي مكان بالولايات المتحدة الامريكية.

\section{ع- تجربة دولة الامارات العربية المتحدة}

بدء دولت الامارات متمثلة في بحلس أبوظبي لشؤون التعليم باستخدام التعلم بالجوال في العملية التعليمية،

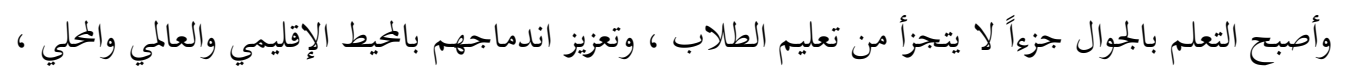
ليكونوا دوما على وعى بكل ما يحدث بالعالم من مُستجدات تكنولوجية وعلمية وثقافية ، ولهذا تم بتهيز جميع المدراس بالتقنيات المتطورة من اجهزة وشبكات انترنت سريعة لتساعد على تفعيل استخدام الجوال في التعليم ، وقد اثبت تلك التجربة بجاحا كبير في العملية التعليمية. 


\section{ه- تجربة المملكة العربية السعودية}

بدأت المملكة بتطبيق التعلم بالجوال في التعليم وذلك بتوجيه من خحادم الحرمين الشريفين الملك عبدالله عام \& \& V اهـ بوضع الخطة الوطنية بتبني التعلم الإلكتروني والتعليم عن بعد في التعليم العالي ، وانشاء مركز وطني

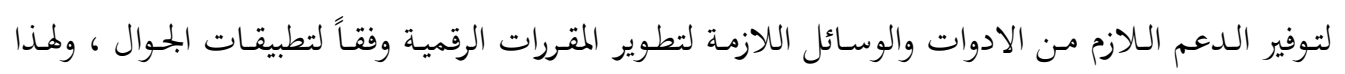
بدأت كثيرا من الجامعة في تنبى فكرة التعلم المتنقل في التعليم ومن هذه الجامعات جامعة المجمعة ،والتي تبنت

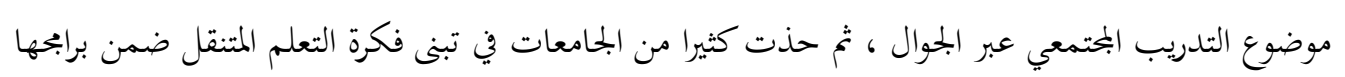

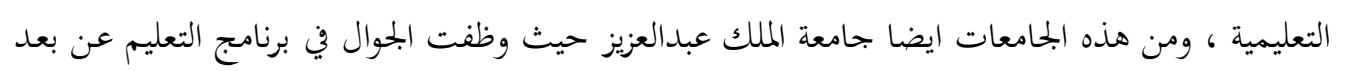
للاستفادة من تطبيقاته التعليمية في البحال التعليمي والتدريبي.

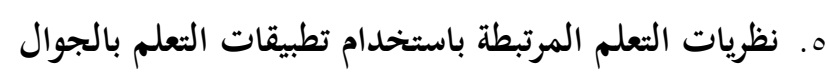

تعددت النظريات التي استند اليها الباحثون في توظيف تطبيقات استخدام التعلم بالجوال ، ويمكن رصد هذه

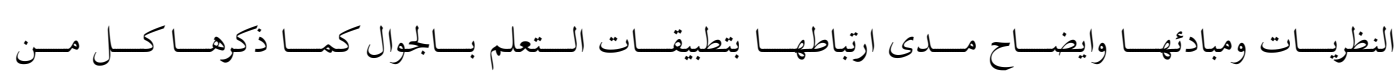

(Smith \&Ragan,2005 Sharples, 2000 ؛keskin\&Metcalf,2012):

النظرية السلوكية وتعنى حدوث التعلم عندما يجد المتعلم التعزيز المناسب عندما يحدث ارتباط بين مثير واستجابة، ومن

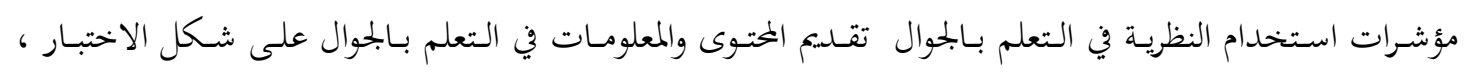
والتدريبات ، وتدريبات الاستماع والتغذية الراجعة. ومن امثلة على الاستخدام تطبيقات خدمة : SMS,MMS) النظرية المعرفية وتعنى اكتساب واعادة تنظيم الخرائط المعرفية التي تمكن المتعلمين من استقبال المعلومات وتخزينها ،

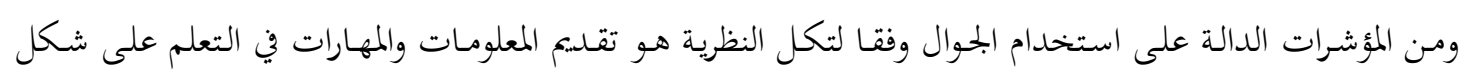
وسائط تعليمية متعددة تتضمن : صور ، وصوت ، وفيديو ، ونصوص ، ورسوم متحركة. ومن التطبيقات التى يمكن استخدامها لتفعيل هذه النظرية خدمة : SMS,MMSEmail, Mobile TV.

النظرية البنائية وتعنى عمليات نشطة تحث المتعلم على بناء افكار ومفاهيم جديدة في ضوء معرفته الحالية والسابقة ،

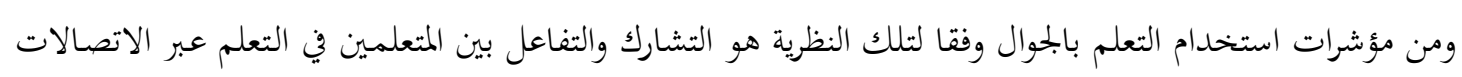
بالهواتف المحولة.

النظرية الاجتماعية وتعنى حدوث التعلم من خلال العلاقات الشخصية ( التفاعل مع البيئة الاجتماعية ) من داخل الفرد

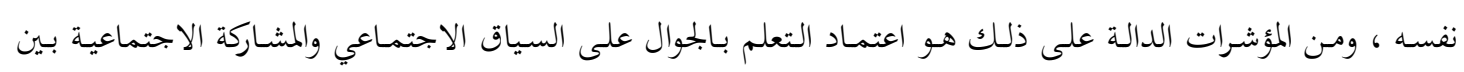
المتعلمين ـ ومن الأمثلة التي تدعم تلك النظرية : الانظمة الافتراضية عبر الجوال ، وادوات الويب. نظرية التعلم مدىى الحياة وتعنى ان التعلم يحدث في كل وقت ومن أي مكان ، ومـن الامثلة لتدعيم تلك النظرية هو استخدام الشبكات الاجتماعية ( المدونات ، والويكى ، وتوتير ، واليوتيوب ) ومنتديات الجوال. 
وقد حرص الباحث في هذه الدراسة على تطبيق مبادئ هذه النظريات عند تصميم البيئة التعليمة القائمة على تطبيقات

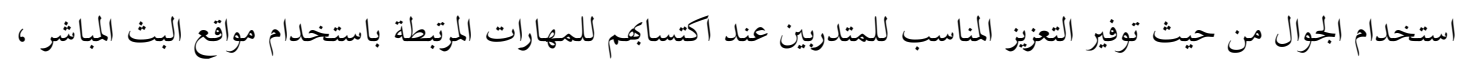

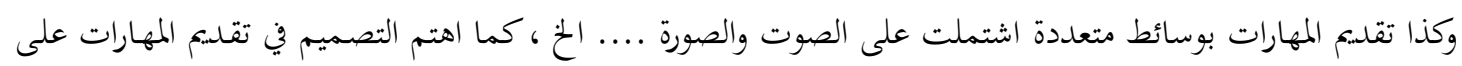
تكامل البناء المعريف لدى المتدربين من حيث التشارك والتفاعل بين المتعلمين.

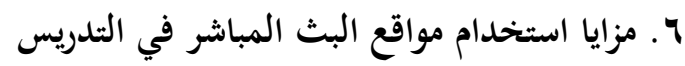

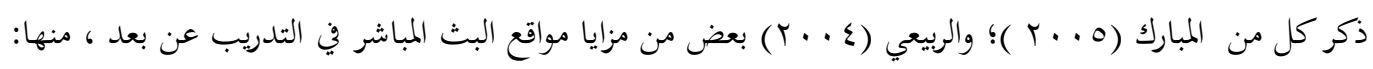
ا - تحقيق مبدأ العدالة والمساواة في الفرص التدريبية والتعليمية ، وبخاصة للمتدربين في الأماكن البعيدة. r - انتشار الثقافة العلمية وانفتاح أبناء البحتمعات النامية على أحدث البرامج التعليمية والتدريبية. r- توحيد المختويات التعليمية والتدريبية في جميع أنخاء البلاد . ع - مساعدة الجهات التعليمية على استيعاب الاعداد الكبيرة من المتدربين. ه- مقليل تكلفة التدريب.

ومن الدراسات السابقة التي اكدت نتائجها أيضا على فوائد مواقع البث المباشر في التدريس ، دراسة ( kanji,2004 ؛ ودراسة 2002, Ragnan \& Nagy التي اكدت نتائجها على فاعلية مواقع البث المباشر في التدريس لمال لهذه المواقع تأثير فعال في تحسين قدرات الدراسين في اكتساهم للمعارف والمهارات بشكل متزامن او غير متزامن في أي وقت وفي أي مكان. وانطلاقا من هذه المزايا تحاول الدراسة الحالية التعرف على فاعلية تصميم بيئة تعلم إلكترونية قائمة على تطبيقات الجوال في التدريب عن بعد لتنمية مهارات استخدام مواقع البث المباشر في التدريس لدى أعضاء هيئة

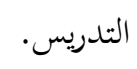

V

تتمثل بناء مراحل تصميم برامج التدريب عن بعد كما ذكرها عبدالرازق (r ( ا Y) وفقاً للشكل التالي:

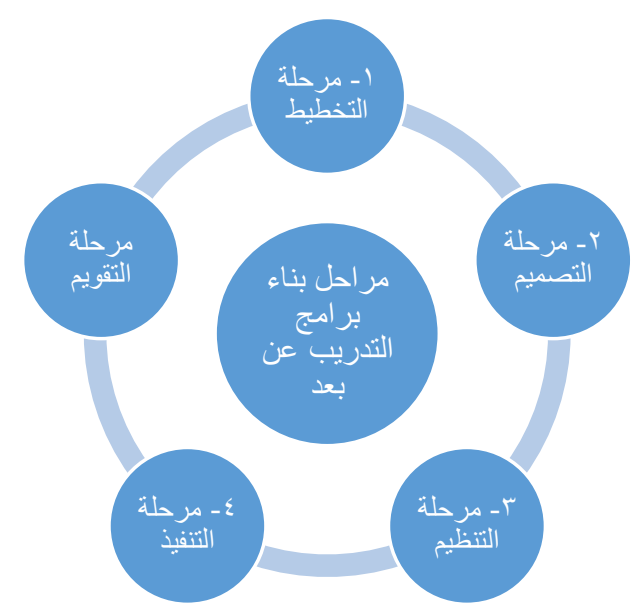

شكل (1) يوضح مراحل بناء برامج التدريب عن بعد 
ويمكن توضيح الخطوات السابقة كما يلي:

المرحلة الأولى: التخطيط

وتتطلب تلك المرحلة تحديد احتياجات المتدربين للعمل على اشباعها، وتحديد الأهداف العامة والخاصة للبرنامج التدريبي، ووضع الإجراءات والاستراتيجيات اللازمة لتنمية مهارات المتدربين.

المرحلة الثانية: التصميم

وهي المرحلة التي يتم فيها تصميم البرنامج التدريب المراد تقديمه عبر تطبيقات الجوال، بجيث يتم ترجمة الاستراتيجيات

والإجراءات التي تمت صياغتها بمرحلة التخطيط لتحقيق الأهداف التدريبية المراد تحقيقها.

المرحلة الثالثة: التنظيم

وفي هذه المرحلة يتم فيها تحديد المدة الزمنية للتدريب والأنشطة التدريبية الخاصة به، وكذا أساليب المتابعة والاشراف على البرنامج التدريبي، وتقديم خدمات الدعم والمساندة.

المرحلة الرابعة: التنفيذ

وفي هذه المرحلة يتم فيها تنفيذ سيناريو التدريب كما تم وضعة في مرحلة التصميم.

المرحلة الخامسة: التقويم

وفي هذه المرحلة يتم تقويم البرنامج التدريب وفقا لعدد من الأسس والمعايير التي يمكن من خلالها اجراء التعديلات لتطوير النظام التدريبي ورسم استراتيجياته المستقبلية. وقد اتبع الباحث في الدراسة الحالية هذه الخطوات السابقة ،وهذا ما سيتضح عند تناول الجانب العملي لإعداد أدوات ومواد الدراسة.

\section{إجراءات البـث}

سارت الدراسة الحالية في الخطوات التالية:

أولا : إعداد قائمة بمهارات استخدام مواقع البث المباشر في التدريس لدى أعضاء هيئة التدريس.

وقد تمت إعداد القائمة من خلال:

- مراجعة البحوث والدراسات السابقة التي اهتمت بتحديد مهارات استخدام مواقع البث المباشر

- الاطلاع على الكتب والأدبيات التربوية ذات الصلة بمهارات استخدام مواقع البث المباشر. - خبرة الباحث في بحال التعلم الإلكتروني. 
من خلال ما تقدم تم التوصل إلي بحموعة من المهارات المتعلقة بمهارات استخدام مواقع البث المباشر

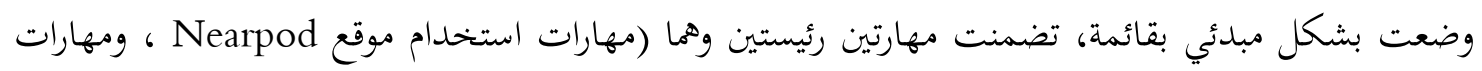

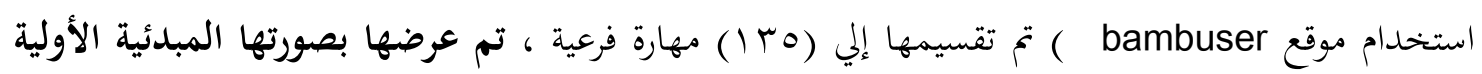

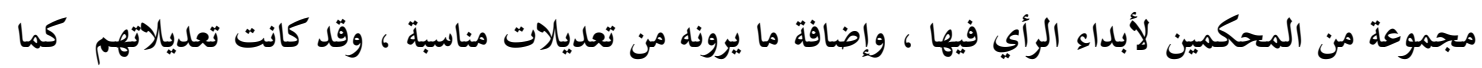

$$
\text { ••تعديل صياغة بعض المهارات. }
$$

وقد تمت اجراء التعديلات وفقا لما اقترحه المحكمون وبهذا أصبحت القائمة في صورةًا النهائية تتكون

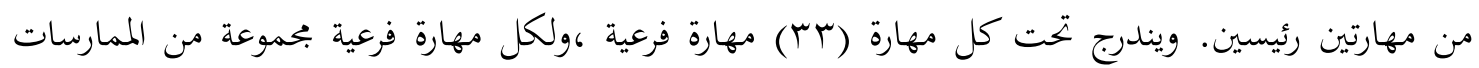
لتحقيق المهارة ، وبذلك أخذت القائمة الشكل النهائي الآتي:

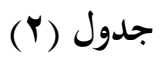

يوضح مهارات استخدام مواقع البث المباشر

المهارة الرئيسة الأولى: استخدام موقع Nearpod وتضمن المهارات الفرعية الآتية: I. الدخول على موقع Nearpod

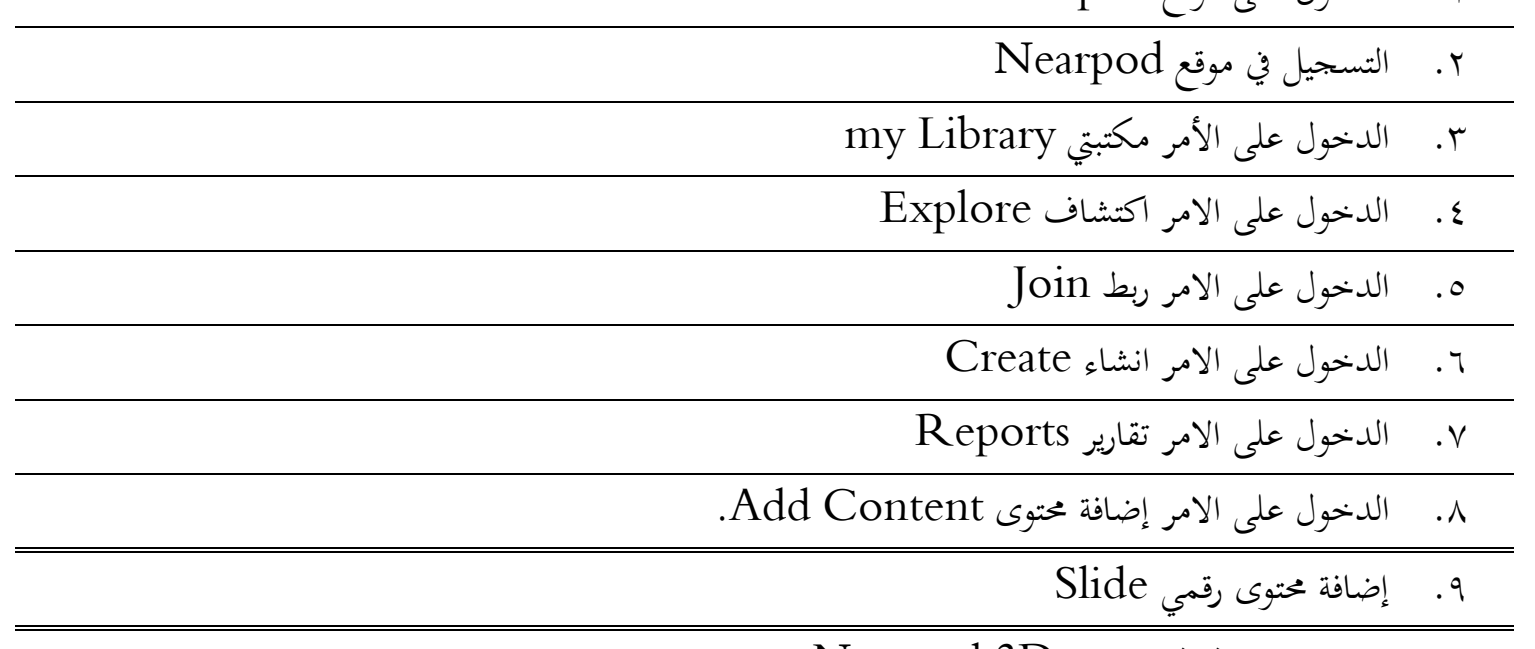

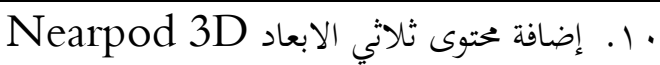

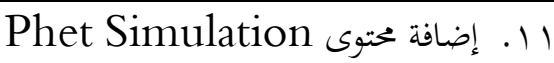

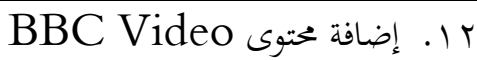

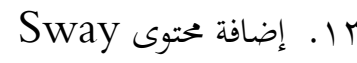

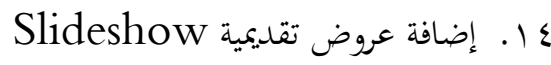

Video 10 


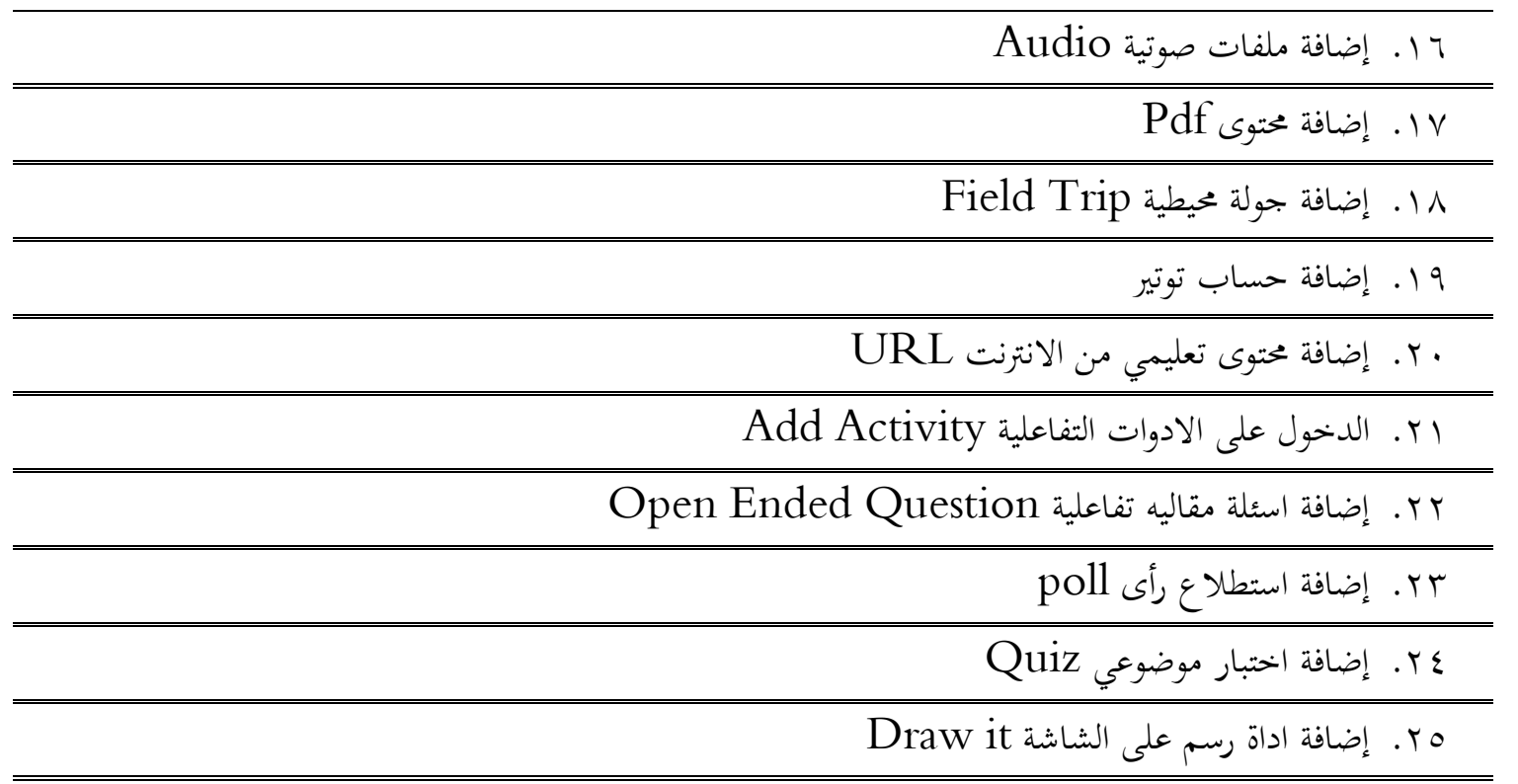

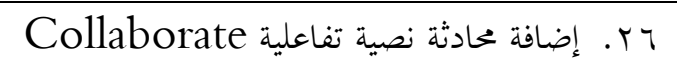

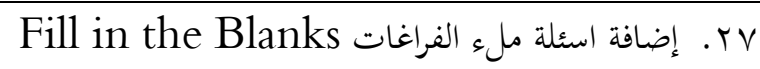

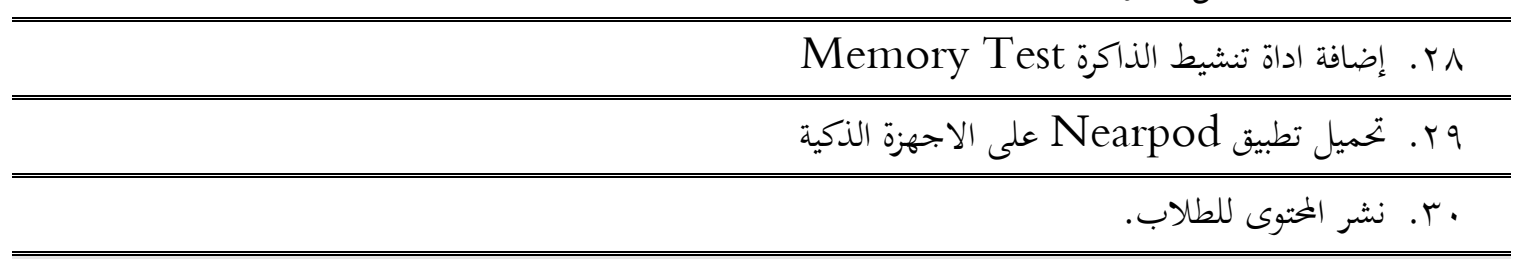

المهارة الرئيسة الثانية : استخدام موقع Bambuser وتضمن المهارات الفرعية الآتية:

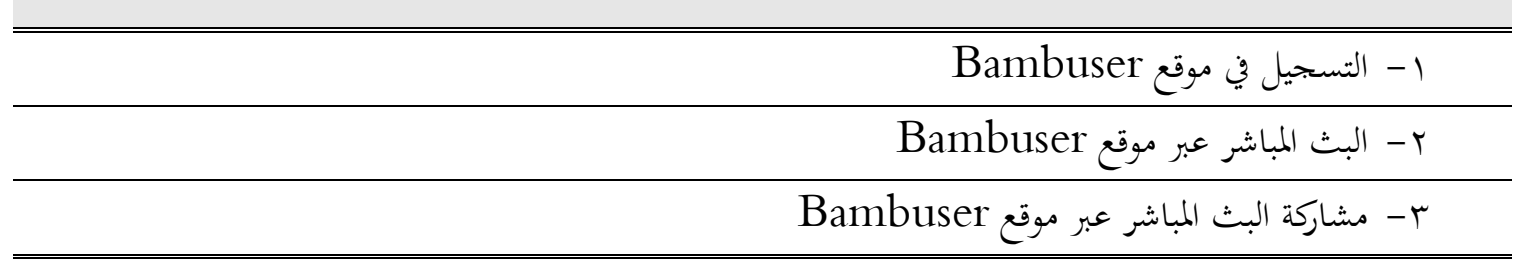

ثانيا: ما التصميم المقترح لتوظيف تطبيقات الجوال في التدريب عن بعد لتنمية مهارات استخدام مواقع البث المباشر في التدريس:

بعد مراجعة الادبيات والدراسات التربوية التي تناولت نماذج التصميم التعليمي ، تم اتباع خطوات النموذج cloobrate mobile ultra , Nearpod, : العام لتصميم البرنامج التدربيي عن بعد عبر تطبيقات الجوال وهى watts app 


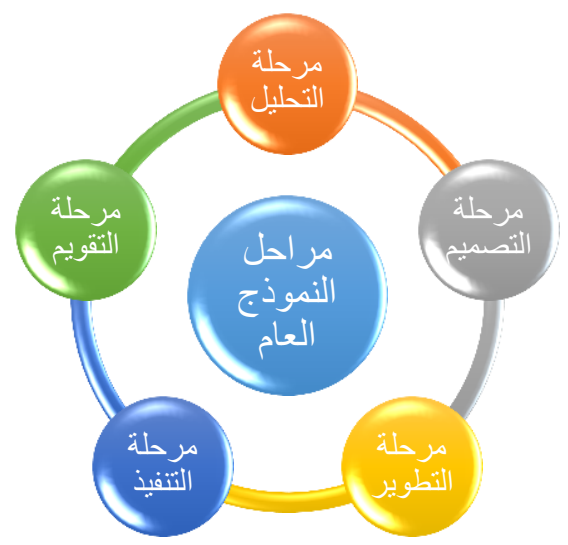

شكل (Y) يوضح النموذج العام لتوظيف استخدام تطبيقات الجوال في التدريب ع بعد

-

في هذه المرحلة تم تحليل الهدف من استخدام تطبيقات الجحوال في تدريب أعضاء هيئة التدريس عن بعد لتنمية مهارقم في استخدام مواقع البـث المباشر في التدريس، وتضمن تحليل وتحديد المتوى بحيث تضمن المتتوى

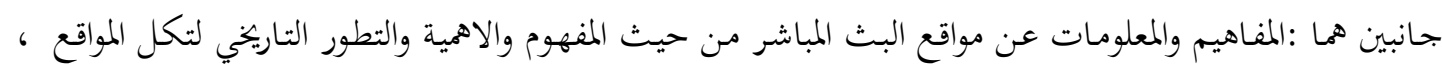
والجانب الاخر تضمن تنمية مهارات اعضاء هيئة التدريس لاستخدام مواقع البث المباشر وهى : موقع البث المباشر

.Nearpod ، Bambuser

Y

في هذه المرحلة تم صياغة الأهداف التعليمية بصورة سلوكية لكل مهارة ، وتحديد استراتيجيات التعلم ،والتي

تمثلت في استخحام استراتيجية التعلم التزامني واللاتزامنى ، والتعلم عن بعد ، وتحديد الوسائط المتعددة والمتمثلة في

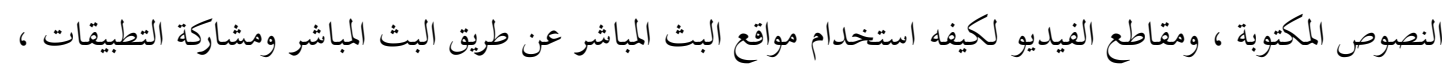
وتم تحديد اساليب التقويم والتي تمثلت في التقويم القبلي والبعدي ، وكتابة سيناريو الخطوات التنفيذية لتصميم تطبيقات الجوال بشكل ورقى يكتوى على العناصر التي سيتضمنها. ب- مرحلة النطوير

وفي هذه المرحلة تم ترجمة السيناريو الموضوع الم مواد تدريبية حقيقية ، حيث تم بتهيز الفصول الافتراضية باستخدام تطبيق cloobrate mobile Ultra ، وكذا تحميل تطبيق Nearpod لعرض الانشطة التفاعلية من خلاله على الطلاب ، وكذا تم عمل بحموعة عبر تطبيق الواتس اب للمناقشة وتبادل الآراء ، ولمشاهدة التسجيلات ومقاطع الفيديو لإعادة عرض شرح المهارات تم تحميلها على تطبيق mobile leering ليستطيع الطلاب مشاهدها في أي وقت وبأي مكان من خلال هواتفهم المحمولة.

ع - عرحلة التنفيذ

في هذه المرحلة تمت عملية استخدام تطبيقات الجوال في تنفيذ البرنامج المقترح باستخدام تطبيقات الجوال 
ين هذه المرحلة تم تحريب التطبيقات للوقوف على سهولة الدنول والاستخدام والتنقل واستخدام جميع

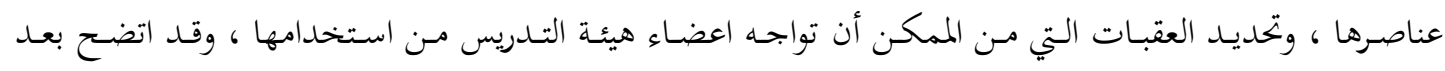
التجريب عدم وجود صعوبات عند الدخول والتنقل والاستخدام.

ثالثا: اعداد الاختبار التحصيلي المعرفي الإلكتروني وفقا لما يلي:

\section{ا ـ . تحديد الهدف من الاختبار}

هدف الاختبار الى قياس الجوانب المعرفية لبعض مهارات استخدام مواقع البث المباشر لدي عينة البحث.

\section{r r تصميم جدول مواصفات الاختبار}

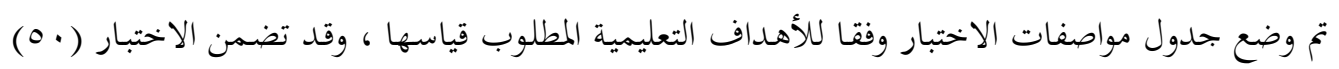

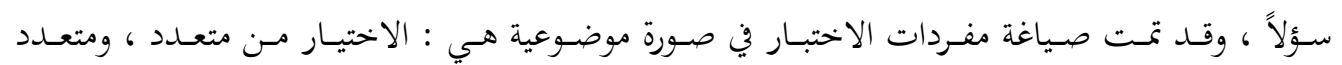
الاستجابات ، والصواب والخطأ ، والمزاوجة ، ومل الفراغات ، وقد روعي عند صياغة بنود الاختبار الأسس التي ينبغي مراعاتا .

\section{تحديد تعليمات الاختبار المعرفي: تئي مراعاكي}

تمت صياغة تعليمات الاختبار بدقة، وقد اشتملت تعليمات الاختبار الهدف من الاختبار، وأنواع الأسئلة ، وبيانات خاصة بالمتدربين.

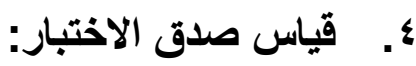

تم التحقق مـن صدق الاختبـار بعرضـة بصورة مبدئية على بحموعـة مـن المحكمسين المتخصصسين في المنـاهج

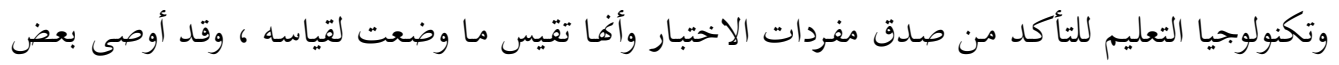

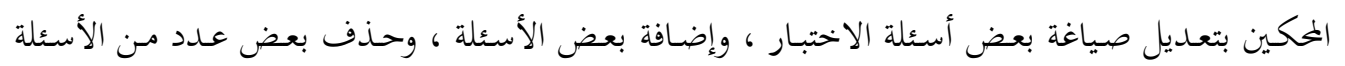
لتكرراهـا في قياس نفس الأهـداف المراد قياسها ، وبعـد اجراء التعديلات المطلوبة أصبح الاختبـار صادقاً ويتكون من (0 ) سؤالاً صالحاً للتطبيق على العينة الاستطلاعية ؛ ليتم حساب معامل الثبات والسهولة والصعوبة والتميزية لأسئلة الاختبار ، وتحديد الزمن المناسب للاخدي لاختبار.

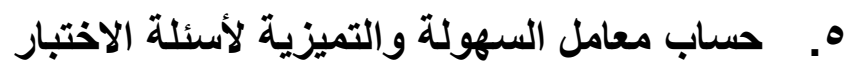

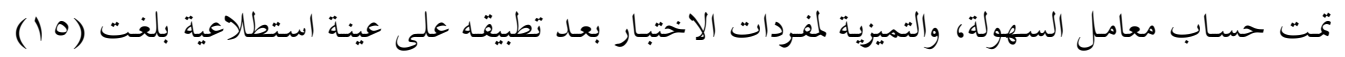

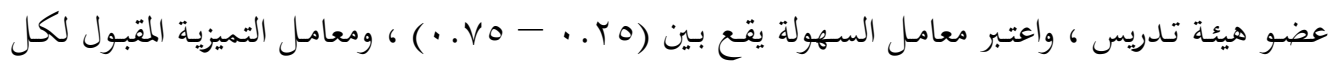

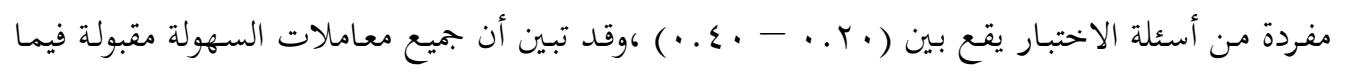
عدا (ع) فقرات بلغ معامل سهولتها (9 . · ) ، وقد تمت استبعادهم ، بينما جاءت معاملاً التميز في الحدود

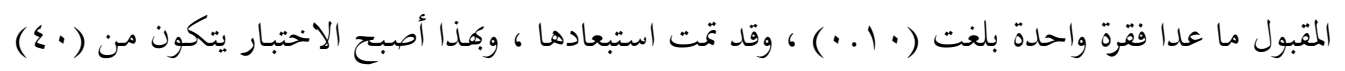
مفردة. 7. حساب معامل ثبات الاختبار

تم حساب معامل الثبات بعد تطبيقه على عينة استطلاعية تكونت من (0 10 ) عضو هيئة تدريس باستخدام

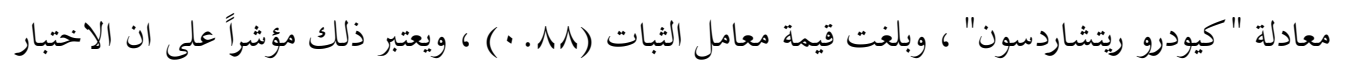


على درجة عالية من الثبات ، وبذلك أصبح الاختبار يشتمل على (•ع) ، وتم تقدير زمن الإجابة عن الاختبار ( • ع) دقيقة ، وبهذا أصبح الاختبار صالح لتصميمه بشكل إليكتروني.

\section{V التصميم الإكتروني للاختبار}

تم تصميم الاختبار وفقا لبرنامج التصميم الإلكتروني (QuizCreator) ليكون متوافق مع أجهزة الجوال ،

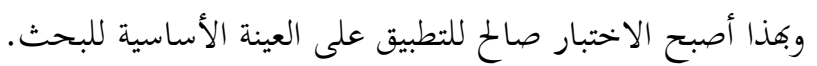

\section{رابعا: اعداد اختبار أداء مهارات استفدام هواقع البث المباشر}

تكونت ورقـة أسئلة الاختبـار مـن تعليميـات لتنفيذ المهام المطلوبـة ، وأحتوت ورقـة أسئلة الاختبـار على المهام

المطلوب من المتدربين القيام بها ، وقد تمت اعداد قائمة تقويم أداء المتدربين والتي تشتمل على المعايير المطلوب توافراهـا

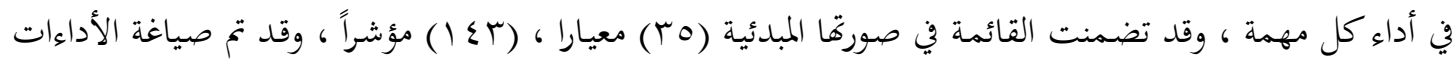
بشكل واضح ودقيق ومحدد

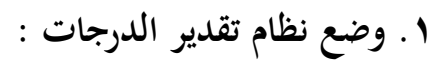

تم استخدم أسلوب التقدير الكمي في تقويم الجانب الأدائي لتنفيذ المهام ، ووزعت الدرجات على (ع) مستويات لمدى توافر مؤشر المعيار في كل مهمة رئيسة وهذه المستويات هي:(متوفر بدرجة كبيرة ، ويأخذ ثلاث درجات ؛ متوفر بدرجة متوسطة ويأحذ درجتين ؛ متوفر بدرجة قليلة ، ويأخذ درجة واحدة ؛ وغير متوفر ، ويأخذ صفر .

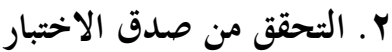

بعد الانتهاء من اعداد الاختبار الأدائي ، تم عرض ورقة تقويم الأداء على بحموعة من المحمين المتخصصين في المناهج وتكنولوجيا التعليم ، للتعرف على آرائهم في مدى كفاية قياس المهارات التي تضمنها البرنامج التدريبي ، ومدى مناسبة تلك المعايير لتقدير أداء المتدربين ، وقد اتفق المحكمون على دقة صياغة المهام مع اجراء بعض التعديلات ، وقد تم

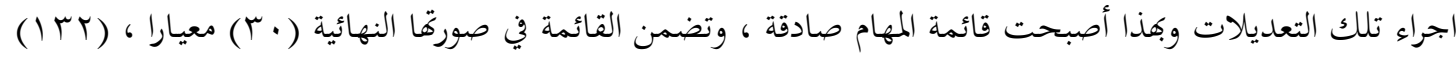
مؤشرا والتي يوضحها جدول (r)

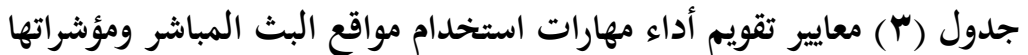

\begin{tabular}{|c|c|c|}
\hline 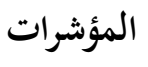 & معايير تقويم أداء مهارات استخدام مواقع البث المباشر & م \\
\hline r & الدخول على موقع Nearpod & 1 \\
\hline 1. & التسجيل في موقع Nearpod & 2 \\
\hline r & الدخول على الأمر مكتبتي my Library & 3 \\
\hline r & الدخول على الامر اكتشاف Explore & 4 \\
\hline$r$ & الدخول على الامر تقارير Reports & 5 \\
\hline 7 & إضافة محتوى رقمي Slide & 6 \\
\hline
\end{tabular}




\begin{tabular}{|c|c|c|}
\hline$\varepsilon$ & Nearpod 3D إضافة محتوى ثلاثي الابعاد & 7 \\
\hline$\bullet$ & Phet Simulation إضافة محتوى & 8 \\
\hline$\bullet$ & إضافة محتوى BBC Video & 9 \\
\hline 0 & إضافة محتوى Sway & 10 \\
\hline$\varepsilon$ & إضافة عروض تقديمية Slideshow & 11 \\
\hline$\varepsilon$ & إضافة ملفات فيديو Video & 12 \\
\hline$r$ & إضافة ملفات صوتية Audio & 13 \\
\hline$\varepsilon$ & إضافة محتوى Pdf & 14 \\
\hline$\varepsilon$ & Field Trip إضافة جولة محيطية & 15 \\
\hline$\varepsilon$ & إضافة حساب توتير & 16 \\
\hline$\bullet$ & إضافة محتوى تعليمي من الانترنت URL & 17 \\
\hline$\mu$ & الدخول على الادوات التفاعلية Add Activity & 18 \\
\hline$\varepsilon$ & إضافة اسئلة مقاليه تفاعلية Open Ended Question & 19 \\
\hline$\varepsilon$ & poll إضافة استطلاع رأى & 20 \\
\hline$\varepsilon$ & إضافة اختبار موضوعي Quiz & 21 \\
\hline$r$ & Draw it إضافة اداة رسم على الشاشة & 22 \\
\hline$\varepsilon$ & Collaborate إضافة محادثة نصية تفاعلية & 23 \\
\hline 7 & Fill in the Blanks إضافة اسئلة ملء الفراغات & 24 \\
\hline $1 \cdot$ & Memory Test إضافة اداة تنشيط الذاكرة & 25 \\
\hline$\varepsilon$ & تحميل تطبيق Nearpod على الاجهزة الذكية & 26 \\
\hline 7 & نشر المحتوى للطلاب. & 27 \\
\hline 7 & التسجيل في موقع Bambuser & 28 \\
\hline$\varepsilon$ & البث المباشر عبر موقع Bambuser & 29 \\
\hline r & مشاركة البث المباشر عبر موقع Bambuser & 30 \\
\hline 132 & 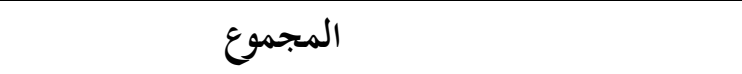 & \\
\hline
\end{tabular}

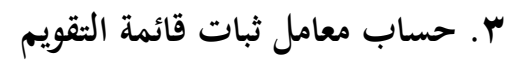

تم حسـاب ثبات قائمسة التقويم باستخدام معادلة نسبة الاتفاق ، حيث تم تطبيق القائمسة على أداء (V) أعضاء هيئة تدريس من العينة الاستطلاعية ، وبعد مرور (• (1) أيام تم التطبيق مرة أخرى على نفس العينة ، وقد حسبت نسبة الاتفاق بين نتائج التطبيقين ، وقد بلغت متوسط نسبة الاتفاق ( (9 . • ) ، وهى نسبة عالية مما يعنى أن القائمة تتصف بالثبات ، وتعد صالحة للنطبيق على عينة البحث الأساسية. 
قام الباحث بتنفيذ التجربة الأساسية للبحث في شهر أبريل ^ 1 ـ ب ، وذلك وفقا للخطوات التالية: •تم عقد لقاء أولى مع عينة البحث ، لتعريفهم بالبرنامج التدريبي وأهدافه ، وتوزيع دليل استخدام تطبيق mobile leering collaborate ultra mobile هعقد لقاء ثاني للتطبيق القبلي لأدوات البحث.

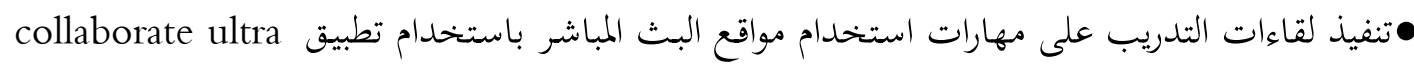
mobile التسجيلات ومقاطع الفيديو لتكرار مشاهدقم لشروحات المهارات ، واستخدام تطبيق Nearpod في عرض الانشطة التفاعلية على الطلاب وتلقى استجابتهم لتقديم التغذية الراجعة الفورية لهم بشكل متزامن. استخدام تطبيق الواتس اب لمناقشة أعضاء هيئة التدريس فيما اكتسبوه من مهارات وتلقى اسئلتهم

$$
\text { والردود عليها بشكل جماعي وأيضا بشكل فردى بشكل غير متزامن. }
$$

بعد الانتهاء من تنفيذ البرنامج التدريبي عبر تطبيقات الجحوال ، تم التطبيق البعدي لأدوات البحـث بمعمل التدريب المتقدم بعمادة التعلم الإلكتروني والتعليم عن بعد بالجامعة الإسلامية .

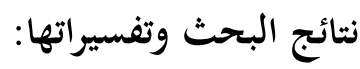

\section{أ - الإجابة على السؤال الأول والذي نص على :}

ما مهارات مواقع البث المباشر الواجب توافرها لدى أعضاء هيئة التدريس لقد تمت الاجابة عن هذا السؤال في الطريقة والاجراءات حيث توصل الباحث إلي عدد (r) مهارة أساسية

$$
\text { يندرج تحتها ( • ع 1) مهارة فرعية انظر الملحق( (1). }
$$

ما التصور المقترح لتوظيف استخدام تطبيقات الجوال في التدريب عن بعد لتنمية بعض مهارات استخدام مواقع

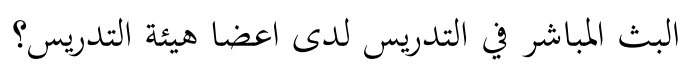
ولإججابة على هذا السؤال ، قام الباحث بمراجعة نماذج تصميم استخدام الجوال في التدريب عن بعد ، وتم تحديد خمس مراجل وهى : التحليل ، والتصميم، والتطوير، التنفيذ ، التقويم ، وقد تم توضيح إجراءات كل مرحلة بالتفصيل في الجزء المتعلق بإجراءات التصميم المقترح، وقد تم إجازة البرنامج المقترح بعض عرضه على بحموعة من المتخصصين في المناهج وتكنولوجيا التعليم ، وبعد بتربته على عينة استطلاعية من أعضاء هيئة التدريس أصبح صالح للتطبيق على العينة الأساسية. 


\section{ج -الإجابة على السؤال الثالث والتحقق من صحة الفرضين الأول والثاني:}

1- نص السؤال الثالث على: ما فاعلية التصور لتوظيف استخدام تطبيقات الجحوال في التدريب عن بعد

لتنمية الجانب المعرفي لبعض مهارات مواقع البث المباشر في التدريس لدى أعضاء هيئة التدريس ؟

ولإجابة عن هذا السؤال تم اختبار صحة الفرض الاول من فروض البحث، والذي ينص على أنه: يوجد

فرق دال احصـائياً عند مستوى دلالة > ا .... بين متوسط درجات التطبيق القبلي ومتوسط درجات

التطبيق البعدي في الاختبار المعرفي لبعض مهارات استخدام مواقع البث المباشر في التدريس لصالح التطبيق

البعدي.

ولتحقق من صحة الفرض الأول تم استخدام اختبار(ت) للعينات المرتبطة لمعرفة الفرق بين المتوسطات

الحسابية والانحرافات المعيارية في الاختبار القبلي والبعدي للمجموعة ودلالة الفروق بينها. والجددول (ع) يبين

النتائج التي تم الوصول إليها.

جدول (ع) لحساب الفرق بين متوسطي درجات التطبيق القبلي والبعدي في الاختبار التحصيلي للجوانب المعرفية لبعض مهارات استخدام مواقع البث المباشر في التدريس

\begin{tabular}{|c|c|c|c|c|c|c|}
\hline مستوى & قيمة (T) & درجة الحرية & المعياري & المتوسطات & $\begin{array}{l}\frac{y}{2} \\
\frac{1}{3} \\
\frac{3}{2} \\
\frac{3}{3}\end{array}$ & التطبيق \\
\hline \multirow[t]{2}{*}{$\cdot .1$} & \multirow[t]{2}{*}{$r \varepsilon . . q$} & \multirow[t]{2}{*}{$r q$} & $r .07$ & $17.0 r$ & $r$. & القبلي \\
\hline & & & $1 . V \wedge$ & rV.qV & $r$. & البعدي \\
\hline
\end{tabular}

يتضح من نتائج الجدول رقم (ع) أن المتوسط الحسابي للتطبيق البعدي قد بلغت (YV.9V) في حين أن المتوسط الحسابي للتطبيق القبلي قد بلغت (ror. 1 ( ) ، كما أن حساب قيمة "ت "لمتوسط الفروق بين التطبيق القبلي

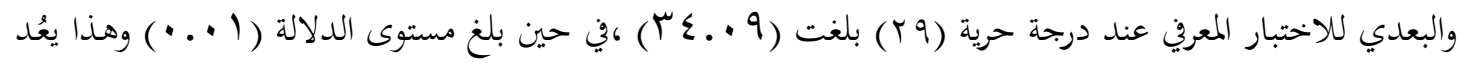

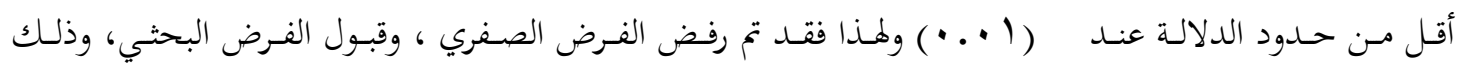
لوجـود فــق دال احصـائياً بـين متوسـطي درجــات التطبيـق في الاختبـار التحصـيلي لصـالح التطبيـق البعـدي. ويمكن إرجاع النتائج السابقة إلى الأثر الكبير لاستخدام تطبيقات الجوال في تنمية التحصيل لبعض مهارات استخدام مواقع البث المباشر في التدريس لدي أعضاء هيئة التدريس.

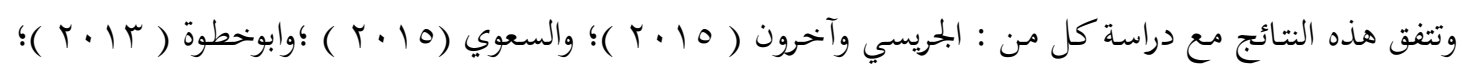

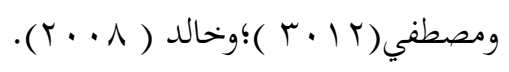


وتعزى هذه النتائج إلى بحموعة من العوامل يمكن رصدها فيما يلي:

1- حرية التواصل مع المتدربين في أي مكان وي أي زمان.

r- البيئة التفاعلية التي يتحها التعلم باستخدام الجوال من حيث المشاركة بين المتدربين والمدرب، وكذا المتدربين

انفسهم.

r- التطبيقات المختارة اعتدت على النقاش والمناقشة المباشرة وغير المباشرة بين المتدربين.

ع - طريقة تقديم المتوى التدريبي عبر تطبيقات الجوال اضفي طابع المتعة على اكتساب المهارات المطلوبة بسهولة

ويسر.

ه- اتاحة التسجيلات للمحتوى التدريبي ساعد المتدربين على مشاهدةما مما سهل في الوصول فهم للمستوى

المطلوب من الاتقان في استخدام مواقع التواصل الاجتماعي.

د-الإجابة عن السؤال الرابع والتحقق من صحة الفرض الثاني:

1- نص السؤال الرابع على: مـا فاعلية توظيف استخدام تطبيقات الجوال في التدريب عن بعد لتنمية بعض

مهارات مواقع البث المباشر في التدريس لدى أعضاء هيئة التدريس ؟

ولإِجابة عن هذا السؤال تم اختبار صحة الفرضيين التاليين:

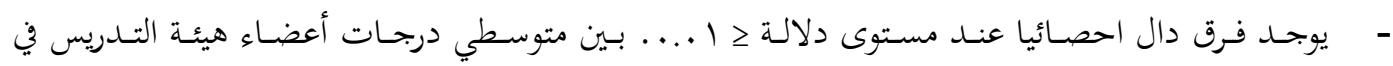

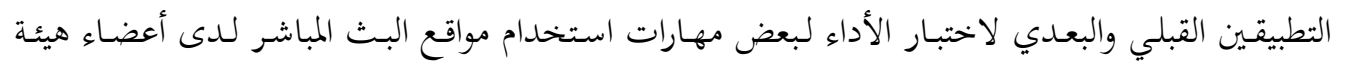

$$
\text { التدريس، ودلك لصالح التطبيق البعدي. }
$$

ولمعرفة صحة الفرض الثاني تم استخدام اختبار(ت) للعينات المرتبطة لمعرفة الفرق بين المتوسطات الحسابية والانخرافات المعيارية في الاختبار القبلي والبعدي للمجموعة ودلالة الفروق بينها. والجدول (0) يبين النتائج التي تم

الوصول لما.

جدول (•) اختبار (ت) لحساب الفرق بين متوسطي درجات التطبيق القبلي والبعدي في اختبار الأداء

التطبيقي

لمهارات استخدام مواقع البث المباشر

\begin{tabular}{|c|c|c|c|c|c|c|}
\hline مستوى الدلالة & قيمة (T) & درجة الحرية & الانمعراف & المتوسطات & $\begin{array}{l}\frac{9}{2} \\
\frac{1}{2} \\
\frac{2}{2} \\
\overline{3} \\
3 \\
3\end{array}$ & التطبيق \\
\hline \multirow[t]{2}{*}{$\cdots \cdot 1$} & \multirow[t]{2}{*}{$\varepsilon 7 . \wedge q$} & \multirow[t]{2}{*}{ rq } & Ir.r人 & $Y 1.77$ & $r$. & قبلي \\
\hline & & & T.YT & 1 1 $9 . \varepsilon$ & $r$. & بعدي \\
\hline
\end{tabular}


يتضح من نتائج الجحدول رقم (0) أن المتوسط الحسابي لنتيجة التطبيق البعدي بلغت (• ع.9 ب ا ) في حين قيمة المتوسط الحسابي للتطبيق القبلي قد بلغت (T7.7. T (Y) ، كما أن حساب نتيجة "ت "لمتوسط الفروق بين التطبيق

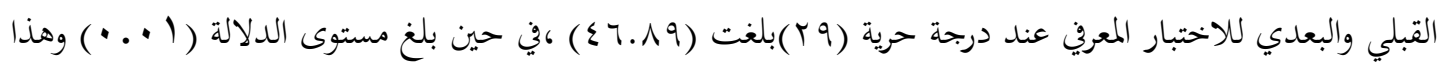
يعُد أقل من حدود الدلالة عند ( ( +. •) ولذذا تم رفض الفرض الصفري ، وقبول الفرض البحثي، وذلك لوجود فرق دال احصائياً بين متوسطي درجات التطبيق في اختبار الأداء التطبيقي لصالح التطبيق البعدي. لعردي.

ويمكن إرجاع النتائج السابقة الأثر الكبير لاستخدام تطبيقات الجوال في التدريب عن بعد في تنمية مهارات استخدم

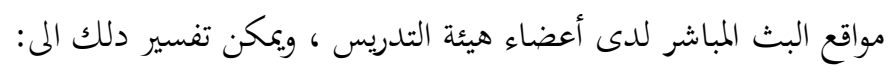

ا. طبيعية عرض المهارة بشكل متزامن عن طريق تطبيق cloobrate ultra mobile الذى يتيح مشاركة عرض كار

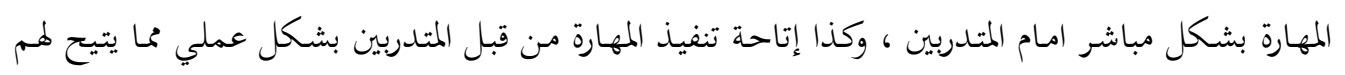

$$
\text { اتقافم للمهارات المطلوب تنفيذها. }
$$

r. استخدام تطبيق Nearpod في عرض الأدوات التفاعلية لمعرفة اتقان المهارات بشكل جيد من قبل المتدربين

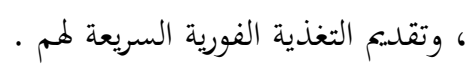

r. استخدام تطبيق Mobile Learing في العرض الغير متزامن لتسجيلات شروحات المهارات بحيث يشاهدها

$$
\text { المتدرب فن أي وقت وفى أي مكان. }
$$

ع. تضمن التصميم امثلة متعددة ومتنوعة لكل مهارة ، مع تلقى تغذية فورية عن أداء كل متدب عن أدائه مما

$$
\text { أدى الى فرص اكتساب المهارات بشكل افضل. }
$$

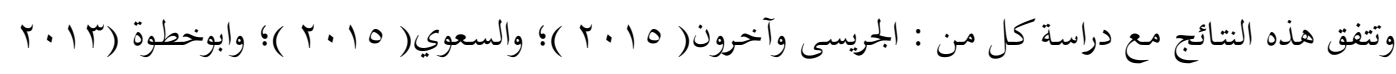

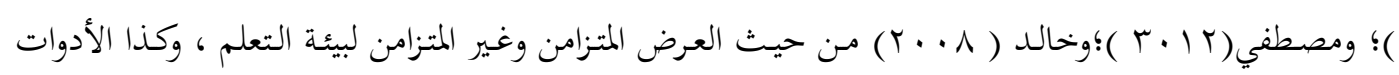

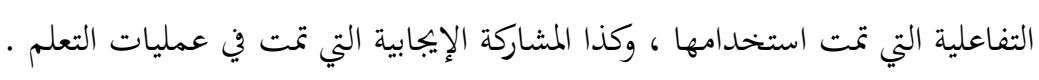

يتضح مما سبق فاعلية توظيف استخدام تطبيقات الجوال في تنمية مهارات استخدام مواقع البث المباشر في

التدريس لدي أعضاء هيئة التدريس بالجامعة الإسلامية، وقد ترجع هذه النتيجة الى المثيرات التعليمية التي اشتمل عليها التصميم المقترح وكذا التواصل المتزامن وغير المتزامن بالمتدربين في أي وقت وفن أي مكان بحيث كل متدرب يتعلم وفقاً لسرعته وامكاناته وكدا وقته المتاح والمناسب لعملية التعلم.

\section{توصيات البحث:}

\section{في ضوء ننائج البحث التي تم التوصل اليها فإن الباحث يوصي بما يلي:}

1. استخدام تطبيقات الجوال في تدريس المواد التعليمية المختلفة للاستفادة من الإمكانيات التي تقدمها.

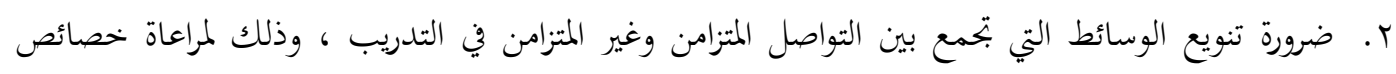
المتدربين وظروف عملهم. 
r. ضرورة تتبنى الجامعات خطة واضحة المعالم ؛ لتنمية القدرة المهارية لأعضاء هيئة التدريس بنظام التدريب عن ـ. عقد دورات متنوعة لتدريب أعضاء هيئة التدريس في الجامعات على استخدام تطبيقات الجوال في التدريس. ه. ضرورة العمل على رفع مستوى التفاعل بين المعلم وطلابه بتفعيل الأنظمة التشاركية من خلال تطبيقات الجوال. I. الاهتمام بتوظيف توظيف التعليم عن بعد في التعليم الجامعي والمعتمد على تقنيات الجوال. مقترحات البحث:

$$
\text { 1. أ. دراسة صعوبات استخدام الجوال في التعليم الجامعي. }
$$

r. دراسة أثر التعلم باستخدام تطبيقات الجوال في التعليم قبل الجامعي على تنمية التفكير الإبداعي .

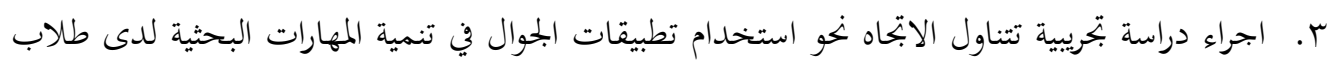

$$
\text { الدراسات العليا. }
$$


ـ ابوخطوة ، السيد عبدالولي (10 • †). فاعلية برنامج مقترح قائم على التدريب الإلكتروني عن بعد في تنمية بعض مهارات التعليم الإلكتروني لدى أعضاء هيئة التدريس ، المؤتمر الدولي الرابع للتعلم الإلكتروني والتعليم عن بعد ، الرياض.

r. اطميزى ، جميل احمد (11 ( + ). تقنيات التعليم الإلكتروني وادواته في خدمة القران الكريم بين النظرية والتطبيق ،

مجلة العلوم والتربية، ع(ب).

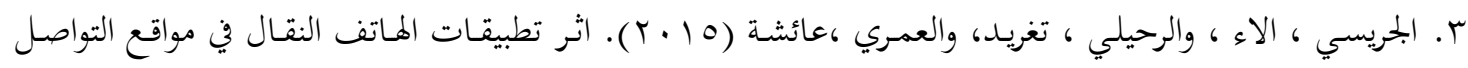
الاجتماعي على تعلم وتعليم القران الكريم لطالبات جامعة طيبة واتجاههن نحوها، المجلة الأردنية، ا (1) (1).

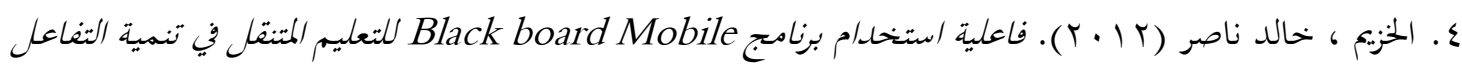
والتحصيل الدرامي لدي طلاب مقرر تاريس الرياضيات في كلية المعلمسين بجامعة الملاك سعود ، رسالة دكتوراه ، جامعة الامام محمد ، المملكة العربية السعودية.

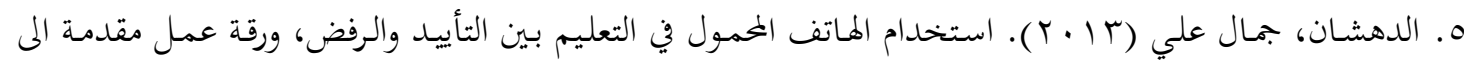
الندوة العلمية الثانية ": نظم التعليم العالي في عصر التنافسية ،كلية التربية ، جامعة كفر الشيخ.

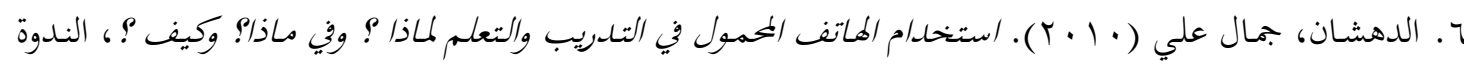

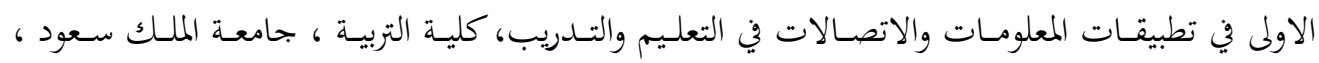
الرياض.

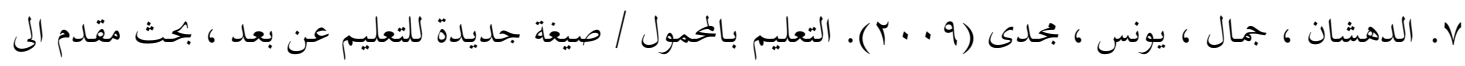

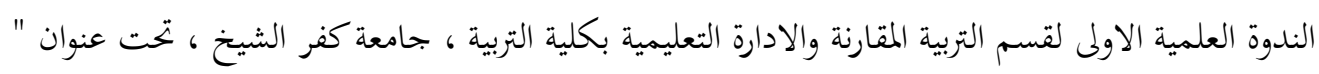

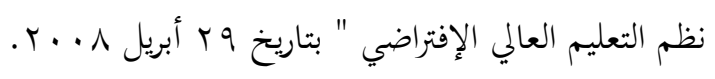

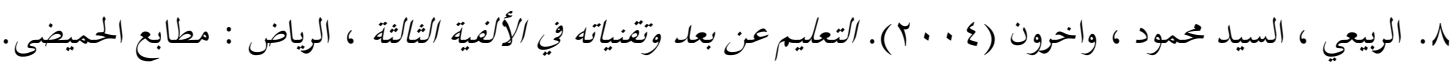

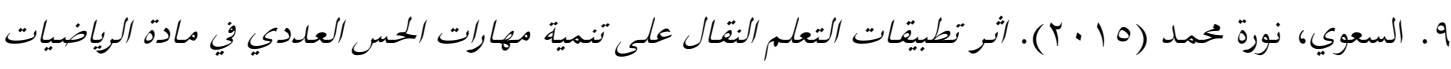

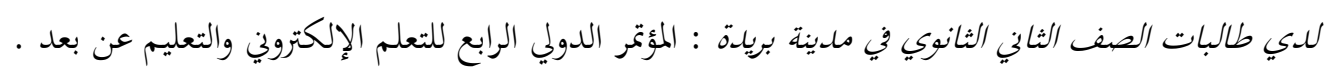

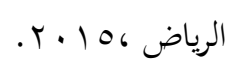

• 1. الشايع، حصة (9 . . ب). تطوير بيئة تعليمية الكترونية متنقلة بجامعة البنات في ضوء معايير التعلم المتنقل، رسالة

$$
\text { دكتوراه، جامعة الاميرة نورة، الرياض. }
$$

ا. العشيرى ، هشام احمد (11 · ب). تكنولوجيا الوسائط المتعددة التعليمة في القرن الحادي والعشرين ، العين : دار

$$
\text { الكتاب الجامعي. }
$$

Y ا. العمرى ، عائشة (10 (Y). اثر تطبيقات الهاتف النقال في مواقع التواصل الاجتماعى على تعلم وتعليم القران الكريم لطالبات جامعة طيبة واتحاههن نحوها ، المجلة الاردنية فن العلوم والتربية ، 11 (1) . 


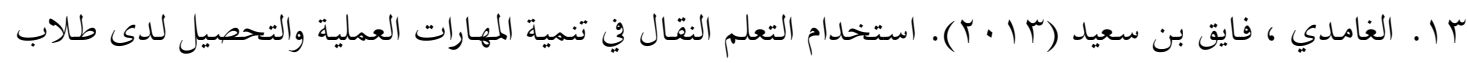
جامعة الباحة ، cybrarians Journal ، 2 (ب).

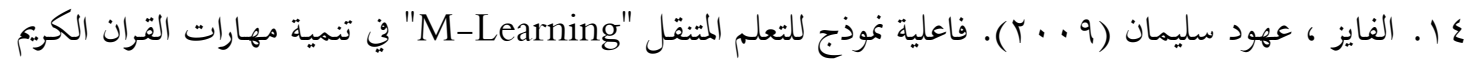
لـدي تلميـذات المرحلـة الابتدائيـة ، رسـالة ماجسـتير كليـة التربيـة ، جامعـة الامـيرة نـورة ، المملكـة العربيـة

$$
\text { السعودية. }
$$

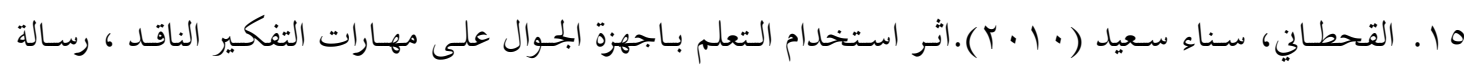
ماجستير ، كلية التربية ، جامعة الملك بعدالعزيز بجدة.

ج 1 . القحطاني، سناء سعيد (11 • †). اثر التعلم النقال علي تنمية مهارات التفكير الناقد لدي طالبات كلية التربية، المؤتمر الدولي الثاني للتعليم الالكتروني والتعليم عن بعد :المركز الوطني للتعلم الإلكتروني والتعليم عن بعد ،

$$
\text { الرياض. }
$$

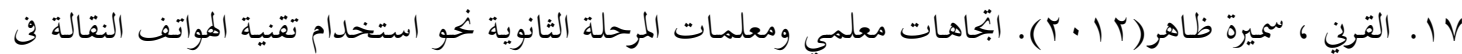
العملية التعليمية بمدينة الرياض ، رسالة ماجستير ، كلية الشرق العربي للدراسـات العليا ، قسـم تقنيـات

$$
\text { التعليم ، المملكة العربية السعودية. }
$$

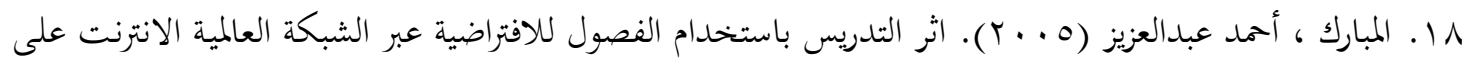
تحصيل طلاب كلية التربية في تقنيات التعليم والاتصال بجامعة الملك سعود ـ رسالة ماجستير ، كلية التربية ،

$$
\text { جامعة الملك سعود بالرياض، المملكة العربية السعودية. }
$$

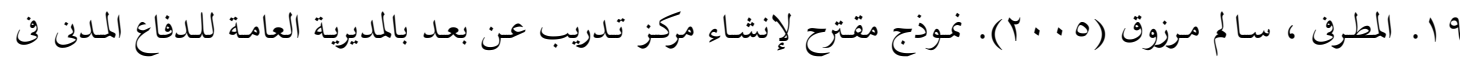

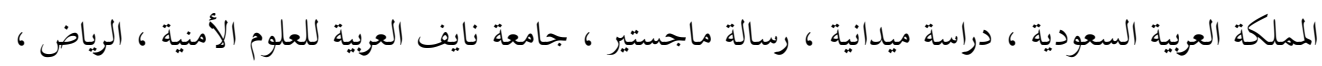

$$
\text { المملكة العربية السعودية. }
$$

• ץ. المهدي ، بحدى طه (^ . ⼴). التعليم الإفتراضي ، فلسفته ، مقوماته ، فرص تطبيقه ، الاسكندرية : دار الجامعة

$$
\text { الجديدة. }
$$

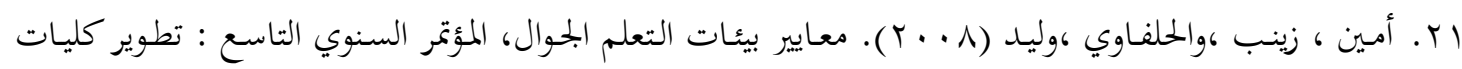

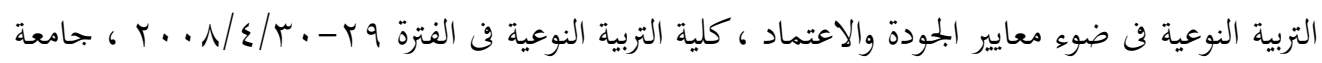

$$
\text { دمياط ، جمهورية مصر العربية. }
$$

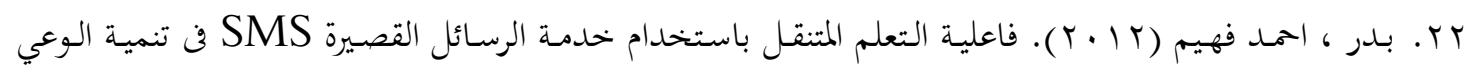
ببعض مصطلحات تكنولوجيا التعليم لدي أخصائي تكنولوجيا التعليم والاتحاه نحو التعليم المتنقل. بحلة كلية

$$
\text { التربية ، جامعة بناه .مصر. }
$$

r r. بنى دومي، حسن احمد (^ . . r). أساسيات التعلم الإلكتروني. عمان: دار وائل. 
ع r. زيدان ، اشرف عبدالعزيز (10 • ب). أثثر التفاعل بين نمط الدعم الإلكتروني المتنقل والاسلوب المعريف في تنمية التحصيل وبقاء اثر التعلم لدى طلاب الدراسات العليا، المؤتمر الدولي الرابع للتعلم الإلكتروني والتعليم عن

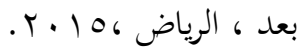

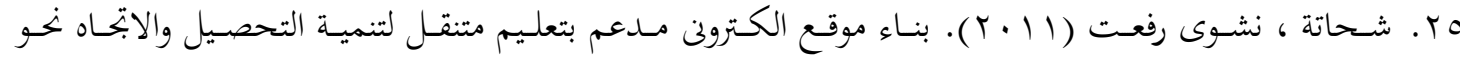

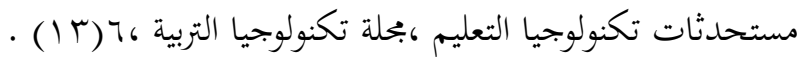

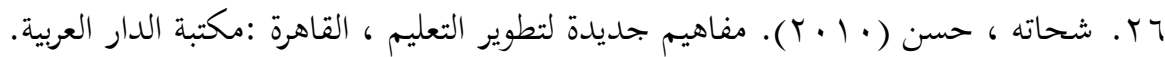

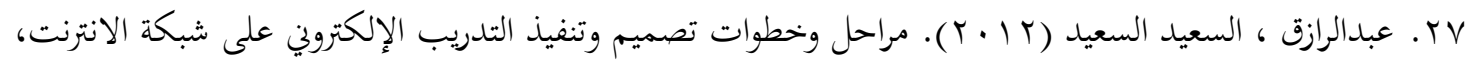
بحلة التعليم الإلكتروني، جامعة المنصورة ، 9 (^).

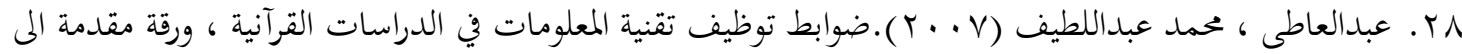
ندوة تقنية المعلومات والعلوم الشرعية والعربية ، الرياض .

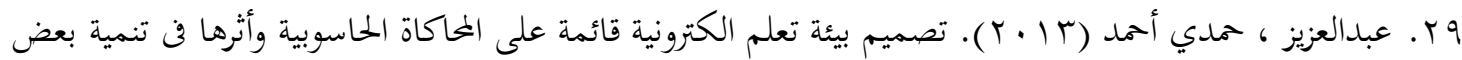
مهارات الاعمال المكتبية وتحسين مهارات عمق التعلم لدى طلاب المدارس الثانوية التجارية ، المحلة الاردنية

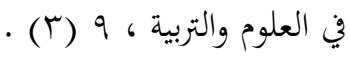

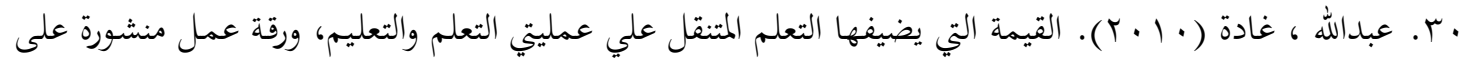
موقع مكتبة التربية العربي. https://www.abegs.org.

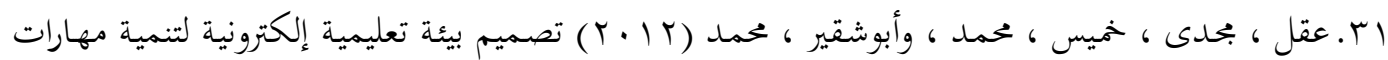

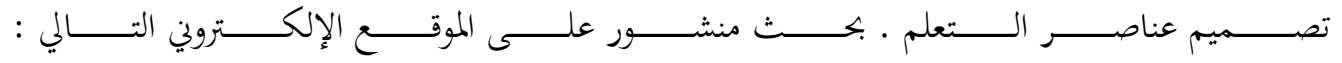
http://site.iugaza.edu.ps/msaqel/wp-content/uploads/web\%20Environment.pdf

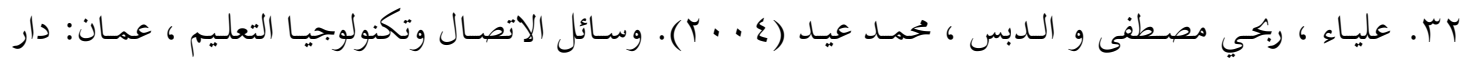
الصفاء ، الأردن.

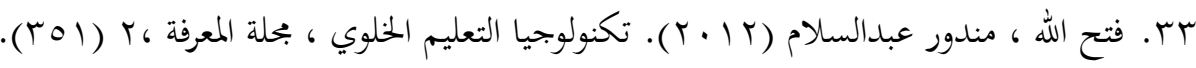

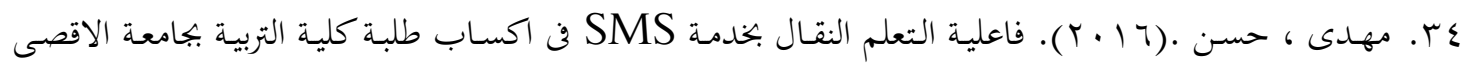
لمفاهيم تكنولوجيا التعليم والاحتفاظ بها ، بحلة جامعة النجاح للأبحاث للعلوم الانسانية، ·؟ (0) .

\section{المراجع الاجنبية}

35. Jonas, D,(2012).Evaluating Apps for Learning and Teaching ,7(4).

36. Chayko ,M (2008).A mobile Learning System for Scaffolding Bird Watching Learning . Albany: state University of New York Press

37. Smith, L.(2005). Social Mobile Applications. Paper presented at Third International Conference Of e- Learning and Distance ,Riyadh ,KSA ,38(4) 
38. Wasilewska ,A,(2009). Mobile Phone Applications in Academic Library service aStudent Feedback, Paper Presented at the International Multiconference on Computer Science and Information Technology ,Mragowo ,Poland.

39. Motivalla,L.(2007). Mobile Learning: A Framework and Evaluation, paper presented at Symposium on The Glorious Quran and Contemporary Technologies: Information Technology, Al Madinah Almunawwarah ,KSA.

40. Menacer ,M(2009). How Do Mobile Devices and Apps Inspire and Facilitate your Teaching? 5 (5).

41. Santosh, B,K (2013). E and M Learning Comparative study, sidho- kanhoBirsha, International Journal on New Trends in Education and Their Implications, July 2013 Volume :4 issue : 3 Article : 08 Issn 1309-6249.

42. Yang, D,C(2010). Promoting Sixth Grader's Number Sense and Learning Attitudes Via Technology- based Environment. Educational Technology and Society, v 13(4).

43. Keskin, O \&Metcalf, D (2012). the current perspectives, theories and practices of mobile Learning (2).

44. Sharples,M.(2005) Towards a theory of mobile learing, cape Town South Africa. http://www.oecd.org/edu/ceri/38360564.pdf

45. Kanji, A., Horiguschi ,H., Suzuki, K ., \& Nambu, M.(2004) Development and evaluation of web - based in - service training system for improving the ict leadership of schoolteachers . Journal of Universal Computer Science, 7 (3). 